\title{
Effects of Parallel Importation and Power Structures on Price Competition in Duopolistic Supply Chains
}

\author{
Luqing Rong $\mathbb{D},{ }^{1}$ Maozeng Xu $\mathbb{D},{ }^{2}$ Xiaofeng Chen $\mathbb{D},{ }^{2}$ and Zhiping $\mathrm{Lu}^{1}$ \\ ${ }^{1}$ School of Economics and Management, Guangxi University of Science and Technology, Liuzhou, Guangxi, China \\ ${ }^{2}$ School of Economics and Management, Chongqing Jiaotong University, Chongqing, China \\ Correspondence should be addressed to Maozeng Xu; 24034090@qq.com
}

Received 3 November 2020; Revised 25 January 2021; Accepted 12 February 2021; Published 26 March 2021

Academic Editor: Yuvraj Gajpal

Copyright (c) 2021 Luqing Rong et al. This is an open access article distributed under the Creative Commons Attribution License, which permits unrestricted use, distribution, and reproduction in any medium, provided the original work is properly cited.

Multinational manufacturers (MNMs) achieve significant gains from product quality and reputation in entering emerging markets while facing many operational risks, such as parallel importation (PI) and market power structures. This paper focuses on a duopolistic supply chain consisting of one MNM and one local manufacturer (LM) in an emerging market with low willingnessto-pay (WTP). Within the game analytical framework, we consider different market power structures and investigate the impact of PI on the manufacturers' price competition, and we further discuss the MNM's countermeasures in high and low WTP markets. We find that PI does not occur when the WTP ratio is below the threshold or the transaction cost is high. Power structures significantly affect the participant's profitability, the LM's gains are maximized if the MNM fully dominates the market, and the MNM loses the minimum if the LM exclusively rules the market. When in codominant structure, the parallel importer achieves maximum gains while the MNM's profits rise in the market WTP ratio interval. PI activities boost the benefits for the LM and the parallel importer, whereas increasing transaction costs diminish those effects and promote the MNM's profitability. PI promotes or deters price competition in duopolistic supply chains depending on power structures. In addition, increasing either the level of product substitution or quality perception restrains PI and improves the LM's earnings, but the latter expands the MNM's losses.

\section{Introduction}

As global economic integration intensifies, an increasing number of manufacturing firms are choosing to develop multinational supply chains to gain more benefits [1] such as inexpensive labor and raw materials, incentives from other governments (e.g., tax reduction and subsidies), and broader markets, while obtaining global operating benefits from production shifting, tax planning, technical advantages, and product brand image [2-4]. In particular, the current global emerging economies have a larger market scale but simultaneously have a lower willingness-to-pay (WTP), while the product quality of the local companies in these countries is far inferior to their foreign rivals, and multinational manufacturers (MNMs) have a strong motivation to enter and capture new markets due to competitive advantages. Operating such multinational supply chains creates opportunities for firms, but there are also significant risk factors, including economic differences, international transfer costs, tariff rates, and international exchange rates. In addition to the above concerns, multinational supply chains will also face the potential threat of parallel importation (PI) [5-9], which obtains genuine products from purchasing inexpensively in a low price-market, resells these products legally by third parties to the market with high demand, and interferes with the pricing strategy and benefits of authentic MNMs [10]. An example in the smartphone industry is Samsung mobile phones, which are favored by the European market for high quality and good reputation and have entered the African market, and their largest competitor, Transsion Technologies Co., Ltd., produces smartphones and is not listed in the international market but holds half of the African market for unique features (i.e., better quality photography and longer battery life). Similar examples can also be found in Asian automotive industry. Tata Motors of India is famous for producing low-cost small cars, which 
accounts for $59 \%$ of the local market share. Because of production costs, risk control, and other factors, the manufacturer has not launched in many international markets. Suzuki, a proficient automobile MNM from Japan, has competed in the Indian market in recent years with the second-largest share. In these cases, to achieve profits in emerging markets with low WTP, MNMs and LMs engage in price competition, which may result in profit losses for the multinational supply chain if a third party purchases $\mathrm{MNMs}^{\prime}$ products from the low-price market and sells at a reasonable price in other high-price markets. Significant price disparity for identical products in different regions leads to substantial parallel import activities, which will also create a market distribution channel for those products that are not authorized by the brand owner, known as gray markets $[7,9,11]$. With the rapid development of cross-border e-commerce and supporting logistics networks, the PI has affected many global supply chain industries [12], especially consumer electronics, medicine, automobiles, and cosmetics [13]. Many countries and regions do not legally prevent or even support PI due to social welfare, since products from unauthorized channels are genuine but less expensive than authorized products [14, 15]. For instance, China has established 12 free trade zones for parallel import automobiles to boost competition in the automotive sector. With high local pharmaceutical prices, Utah has also passed legislation that allows the government to reimport drugs at wholesale prices from Canada [16].

In addition to countering PI, the MNM entering an emerging market has to manage the competitive relationship with the local manufacturer (LM), which involves market power structures. For example, the competition between $3 \mathrm{M}$ and Sinotextiles Corporation in the Chinese market for premium protective masks is a Stackelberg game, and the former has held $90 \%$ of the market share and dominated the market price for more than a decade [17]. With the outbreak of the COVID-19 epidemic, the latter gradually came to account for $50 \%$ of the market share and decided on the price of masks together with $3 \mathrm{M}$, which can be considered a Nash game. Another example is the battle between Pepsi and CocaCola, in which the two are evenly matched for market share in some countries, while the market in other countries has earned Pepsi (or Coca-Cola) wide favor for consumers' taste preferences [18]. Namely, power structures, including Nash and Stackelberg games, prevail and influence stakeholder competition. Based on the examples and discussion above, the following questions deserve concern:

(i) Many emerging economies encourage MNMs to launch premium products in local markets for consumer welfare. Will parallel importation hinder competition and cause higher product pricing?

(ii) Intuitively, PI terminates the manufacturer's monopoly and reduces product demand in the high WTP market. Is this true? Will PI benefit the MNM by moderating the two market prices to achieve greater earnings in the low WTP market? What does PI mean for the LM? (iii) If the MNM deters the parallel importer with product prices, are the strategies challenged by market power structures? What are the effects of the different power structures on the manufacturers and the parallel importer?

(iv) The WTP disparity for the authorized product in different markets creates arbitrage opportunities. How does the parallel importer decide on the timing to engage in PI activities? How do the nonnegligible transaction costs in PI affect the benefits of participants in the multinational supply chain?

This study explores the above questions by offering theoretical and practical contributions. First, under the widespread presence of PI, this paper explores the trade-off between the MNM's launching products in the low WTP market and deterring the gray products in the high-price market. Second, we investigate the impact of the power structures on the MNM's managing PI and identify that parallel importer arbitrage benefits the MNM in some settings, which is also a departure from our intuition. Third, there are various strategies to control PI in practice, and it is still confusing for the MNM to decide in an uncertain environment. Hence, we further discuss the impact of sensitive factors (such as WTP, quality perception, and transaction cost) on the MNM's decisions under different scenarios. The analysis will help the MNM consider how to compete with the emerging market rival while also contributing to the multinational supply chain literature.

The remainder of the paper proceeds as follows. In Section 2, we propose the problem description and the model hypothesis. In Section 3, we develop the equilibrium profits of two manufacturers and one parallel importer with and without PI in scenarios and demonstrate the impact of the power structure on pricing competition and participants' revenue of the supply chain. In Section 4, we present numerical examples and extensions. In Section 5, we draw conclusions and denote possible limitations to our study and suggest future research directions in the future. And, technical proofs of the quantitative analytical results are presented in the Appendix.

\section{Literature Review}

This work is closely linked with three research aspects: (1) literature on PI issues and gray markets, (2) power structures among members of a supply chain, and (3) pricing strategies under PI.

With the gradual elimination of regional trade barriers, there is increasing concern regarding the first aspect. Some papers concentrate on the domestic gray markets. Ahmadi et al. [12] discuss the reasons for the emergence of domestic gray markets and concentrate on how contract design coordinates the product supply chain affected by them. Although gray markets sell excess product inventory and reduce retailers' competitive pressure in practice, they will erode manufacturers' market profits through low prices. $\mathrm{Hu}$ et al. [19] analyze and argue that all unit discount schemes are beneficial to suppliers when the inventory holds parallel 
importers' costs and suppliers' scale economic advantage vary in a certain range. Under uncertain domestic demand, Altug [20] extends a model to discourage price competition between the authorized channel and gray channels by optimizing the stocking decision. Moreover, the majority of studies are absorbed in international gray markets and PIs [21-24], which result from price differentials between regions. Although PI impacts MNMs' price discrimination and earnings [25, 26], Ahmadi and Yang [5] propose a game model with two countries and three stages and find that PI will benefit MNMs in some conditions. In some cases, conflicting incentives also lead to international gray markets. Shao et al. [11] indicate that retailers' product diversion through types of "local gray markets" and "bootlegging" will undermine the benefits of manufacturers and retailers. PI not only threatens authentic firms' profits but also challenges competitors. Li et al. [27] examine PI in different duopoly supply chains by regarding manufacturers' product quality differential and market competition and point out that there is a trade-off between market encroachment and demand expansion on MNM's benefits. Since product quality may be endogenous, Ishikawa et al. [28] investigate the impact of repair services on PI. The research demonstrates that warranty services can cope with parallel importers when increasing product damage rates, causing a reduction in consumer welfare in countries. To manage gray diversion in the luxury market, Huang et al. [29] propose three marketing channel strategies (including selling simultaneously, selling sequentially, or selling only in high-price markets). They confirm that these measures are valid, while the activities will also relieve the dual marginal effect and boost participants' revenue. Countering the traditional belief, Cao and Zhang [30] argue that gray distribution induces MNMs to improve product quality when both markets approach WTP. The analysis also illustrates that retailers in both high- and lowprice markets have incentives to pursue PI activities.

The second aspect concerns market power structures; the term "power" refers to the participant's ability in a supply chain to intervene in the market and determine the game sequence [31,32]. Choi [33] analyses the participants' profits of a supply chain composed of two manufacturers and a common retailer under three power structures, which include manufacturer-led Stackelberg (MS), retailer-led Stackelberg (RS), and vertical Nash. Based on the supply chain members' power imbalance, Edirisinghe et al. [32] extend the analysis model of Choi [33] and enlarge the power structures to seven types, concluding that neither MS or RS are stable structures for benefits in generalized settings. Logically, the researcher's preference for some power structure often depends on the participants' capacity and resources available in a game.

The third aspect concerns the pricing strategies with respect to gray markets. Yang et al. [34] investigate the pricing strategies of "Local", "Uniform," and "Friction" and compare them with the strategies of "Global" and proactive and conclude that the measures to prevent or allow PI depend on the global profit and authentic manufacturers' sales. With regard to gray marketing, Lee and Hsiao [21] develop a duopoly model and study pricing issues based on the Cournot assumption. Regarding the distributor's profit maximization, the manufacturers use quantitative tools to model and interpose gray markets. Altug and Sahin [16] consider pricing decisions according to a pharmaceutical firm's launch strategies and propose that high-price deterrence and low-price adjustment tolerance could be adopted under different threshold ratio intervals of WTP in high and low markets, respectively, and that no launch is useful in some conditions. To address the substantial consumer burden of high pricing for some critical drugs, Iravani et al. [35] analyze and compare the impact of external reference pricing (ERP) and gray markets on controlling drug prices. The analysis shows that the government's permitting the drug diversion from the low-price market to gray markets will enhance social welfare and multinational pharmaceutical firms' revenue more than adopting ERP. In addition, studies on deterring parallel imports are advanced from the perspectives of product services [10], organizational structures [36], consumer rebates [37], channel control [38], warranties [39], information sharing [40], etc.

Most of the above involve how monopoly manufacturers manage PI markets and discuss the impact of gray markets on manufacturers: there are few on the multinational supply chain with respect to multiple manufacturers' production of alternative products and responding to the PI's threat concurrently. Actually, the products in some markets that satisfy the demand may be from several alternative manufacturers, and manufacturers' price competition will also induce PI. However, there is little research on PI caused by price competition in the low WTP market. The most relevant research is that of Shavandi et al. [41], but the analysis only focuses on a supply chain consisting of two manufacturers and one parallel importer in the power structure of vertical Nash and assumes that participants have equal influence on the market. Logically speaking, there are many market impact possibilities for the MNM and the LM in the supply chain, but the parallel importer often relies on manufacturers by eventually acting in the game analysis framework. Additionally, the profitability of gray markets largely depends on manufacturers' pricing decisions. Furthermore, the latest available studies $[16,42,43]$ on multinational supply chains deterring PI neglect to capture the transaction costs involved in parallel import activities, which are essential for third-party arbitrage.

\section{Problem Description and Hypothesis}

We consider that two manufacturers produce the same function but different brands and styles of products in two geographically separated markets (marked with Market 1 and Market 2) and that consumers in Market 1 have a lower WTP for the product relative to consumers in Market 2. Manufacturer 1 (he) is a multinational manufacturer that produces branded reputable products 1 and sells in Markets 1 and 2. Manufacturer 2 (she) is a local manufacturer who only produces generic branded products 2 and retails in Market 1. Furthermore, we assume that the potential demand scale of Markets 1 and 2 is 1. Normally, Market 1 is in duopoly competition for the 
products of Manufacturers 1 and 2, and Market 2 is monopolized by Manufacturer 1.

Consumers' WTP for product 1 in Markets 1 and 2 are expressed in terms of $v_{1}$ and $v_{2}$, respectively, and they satisfy the uniform distribution of $\left(0, \bar{v}_{1}\right)$ and $\left(0, \bar{v}_{2}\right)$. To reflect that consumers in Market 2 have higher valuations and preferences for the product, we suppose $\bar{v}_{1}<\bar{v}_{2}$ and deploy $R=\bar{v}_{2} / \bar{v}_{1}$ to capture the WTP gap in various markets.

Parallel importers shifting Manufacturer 1's products from the low WTP market to the high WTP market will involve transaction costs [44-47], such as import tariffs, transportation costs, and warehousing costs, and $t$ denotes transaction costs for each product 1 in the PI market. Based on the fact that the parallel importer will leverage reliable and efficient logistics channels $[48,49]$ and the tariff policies adopted by some countries for particular commodities (e.g., pharmaceuticals and electronics) $[16,50]$, we presume that the transaction costs are not in the basic model $[11,51]$ and will release this assumption in the numerical example and extensions 4.3 .

We also assume that, in Market 1, the price and the product substitution rate have significant impacts on the demand [33, 41, 52]. For one, the higher the price, the lower the product demand; for another, the products of two manufacturers in the low WTP market have a certain substitution rate which denotes $\eta \in[0,1]$, and the higher the product substitutability, the higher the manufacturers' market demand. Referring to Yao et al. [53], Banker et al. [54], and Taleizadeh et al. [39], the demand function for the two manufacturers in Market 1 is constructed as follows:

$$
q_{i 1}=1-\frac{p_{i 1}}{\bar{v}_{1}}+\eta \frac{p_{j 1}}{\bar{v}_{1}}, \quad \forall i=1,2 ; j=3-i,
$$

where $q_{i 1}$ represents the product demand in Market 1 for Manufacturer $i(i=1,2), 1$ represents the potential demand in Market $1, p_{i 1}$ represents the product price of Manufacturer $i$ in Market 1 , and $p_{k 1}$ indicates the price of manufacturer $k$ in Market 1 . To ensure $q_{i 1} \in[0,1]$, we specify $p_{i 1} \in\left[0, \bar{v}_{1}\right]$ and $p_{k 1} \in\left[0, \bar{v}_{1}\right]$. Because those factors, including product 1 , have a low WTP in Market 1 and the manufacturers compete for the market, a third party parallel importer can buy the MNM's products in the market at the low price $p_{11}$ and transfer to the high price market to sell at $p_{3}$; then, we obtain $p_{11} \leq p_{3} \leq p_{12}$.

The quality perception of the PI product obtained by consumers will be lower than that through authorized channels because of the lack of warranty, after-sales service, and product compatibility problems of PI products, as well as the loss of product quality due to nonstandard storage, transportation, and packaging $[7,16] . \gamma$ denotes the perceived quality of PI products and takes the range of $[0,1]$. Concurrently, the two market demands hold no shifts, and the price change in one market does not alter the demand in the other market.

In Market 2, we assume that product 1's demand is mainly influenced by the price [11]. If PI prevails, the market will be dominated by product 1 from Manufacturer 1 and the parallel importer, namely, the MNM will face a market cannibalization effect. At this point, there are three consumer strategies in Market 2, including buying official channel products, buying parallel import products, and not buying products. If product 1's official price is $p_{12}$ and the PI market price $p_{3}$, the consumer's valuation for product 1 is $v_{2}$, and when the product surplus value purchased from official channels is greater than that from PI, viz., $v_{2}-p_{12} \geq \gamma v_{2}-p_{3}$, the consumer purchases Manufacturer 1 's authorized products. Otherwise, the consumer turns to the PI market. Moreover, for consumers who buy authorized or parallel imports without differences, the product valuation is $v_{2}^{1}=p_{12}-p_{3} / 1-\gamma$. Similarly, for consumers who buy or do not buy PI products without a gap, the product valuation equals $v_{2}^{2}=p_{3} / \gamma$. Therefore, consumers who have a valuation above $v_{2}^{1}$ choose the authorized product demand, and Manufacturer 1's product demand in Market 2 is derived as

$$
q_{12}=\int_{v_{2}^{1}}^{\bar{v}_{2}} \frac{1}{\bar{v}_{2}} \mathrm{~d} x=1-\frac{p_{12}-p_{3}}{\bar{v}_{2}(1-\gamma)} .
$$

Consumers who value product 1 above $v_{2}^{2}$ and less than $v_{2}^{1}$ will choose the PI product, and the parallel importer's demand in Market 2 is

$$
q_{3}=\int_{v_{2}^{2}}^{v_{2}^{1}} \frac{1}{\bar{v}_{2}} \mathrm{~d} x=\frac{1}{\bar{v}_{2} \gamma(1-\gamma)}\left(\gamma p_{12}-p_{3}\right) \text {. }
$$

In contrast, if Market 2 does not suffer from PI, consumers who purchase Manufacturer 1's product or not with no difference will assess its valuation as $v_{2}^{3}=p_{12}$, and Manufacturer 1's demand is

$$
q_{12}^{0}=1-\frac{p_{12}}{\bar{v}_{2}}
$$

We suppose that the parallel importer's decision-making largely depends on the manufacturers' pricing strategies $[5,9,55]$. Manufacturer 1 preferentially determines the price in Markets 1 and 2 as $p_{11}$ and $p_{12}$, respectively, and the parallel importer subsequently defines $p_{3}$ to optimize profits and reimport the products to Market 2 under profitable conditions. The problem can be formulated as

$$
\pi_{3}\left(p_{3} \mid p_{11}, p_{12}\right)=\max _{p_{3}}\left\{q_{3}\left(p_{3}-p_{11}\right)\right\}=\max _{p_{3}}\left\{\frac{1}{\bar{v}_{2} \gamma(1-\gamma)}\left(\gamma p_{12}-p_{3}\right)\left(p_{3}-p_{11}\right)\right\} .
$$

Hence, $p_{3}=\gamma p_{12}+p_{11} / 2$ is the optimal price to ensure the parallel importer's maximum profits. In particular, $\mathrm{PI}$ is lucrative when $\gamma p_{12} \geq p_{3}$ and $p_{3} \geq p_{11}$ are satisfied, which equals $p_{11} \leq \gamma p_{12}$. Under these conditions, the parallel importer procures product 1 in Market 1 at a low price and arbitrage in Market 2. Otherwise, PI will not occur. 
Moreover, the MNM's profits in both markets can be reaped separately, and the parallel importer's optimal pricing is

$$
p_{3}=\min \left(\frac{\gamma p_{12}+p_{11}}{2}, \gamma p_{12}\right)
$$

Additionally, we assume that only the MNM's products are the parallel importer's target [43], while the LM's seldom suffers. MNM' products are more familiar to markets because of their better reputation and quality. For example, Apple and Samsung mobile phones are flowing into the PI market, while products such as Huawei and Transsion rarely appear. Hence, three participants appear in Market 1, including Manufacturers 1 and 2 and the parallel importer who purchases products 1 . Figure 1 shows the background.

\section{Model Analysis}

If the MNM not only competes in Market 1 with the LM but also deals with the impact of the PI market, the price strategy will face challenges.

4.1. Supply Chain Structure without Parallel Import. First, we discuss the multinational supply chain structure without PI as a basic benchmark model. When the condition meets $p_{11}>\gamma p_{12}$ and price competition occurs in Market 1 , there are no PI activities. The profit functions of Manufacturers 1 and 2 are presented as follows:

$$
\pi_{1}=p_{11} q_{11}+p_{12} q_{12}=p_{11}\left(1-\frac{p_{11}}{\bar{v}_{1}}+\eta \frac{p_{21}}{\bar{v}_{1}}\right)+p_{12}\left(1-\frac{p_{12}}{\bar{v}_{2}}\right)
$$

$$
\pi_{2}=p_{21} q_{21}=p_{21}\left(1-\frac{p_{21}}{\bar{v}_{1}}+\eta \frac{p_{11}}{\bar{v}_{1}}\right) \text {. }
$$

Based on the studies $[33,56,57]$, we find that the participant who owns market power will act first to influence global decision-making and that there are three different power structures in the discussion. The first scenario (S1) is MNM-led, in which the MNM first determines his price in Markets 1 and 2, and the LM decides her price in Market 1 after Manufacturer 1; the second scenario 2 (S2) is LM-led, in which the LM first decides the price, and the MNM then decides the prices in the two markets. The third scenario (S3) is the two collective manufacturers-led scenario, in which the MNM and the LM concurrently determine the product prices in Markets 1 and 2, respectively. The decision sequence of the participants in different scenarios is shown in Figure 2. The optimal solutions of decision variables under different scenarios can be obtained (see Table 1).

Proposition 1. The price and quantity of the MNM's product in Market 2 are $0.5 \bar{v}_{2}$ and 0.5 , respectively, in different scenarios.

Proposition 1 implies that the MNM's decision-making in the two markets is independent when the supply chain is not affected by PI. In addition, the MNM effectively divides the markets, and the optimal decision-making holds owing to the monopoly advantage in the high-price market.

Proposition 2. In Market 1, if

(1) Manufacturer 1 is the Stackelberg leader, and Manufacturer 2 will have lower prices and more sales than Manufacturer 1

(2) Manufacturer 2 is the Stackelberg leader, and Manufacturer 1 will realize a lower price and more sales than manufacturer 2

(3) Two manufacturers dominate the market in unison, and both determine simultaneously to minimize respective prices, resulting in the largest product sales and the equal price in the low willingness-to-pay market

Proposition 3. When Manufacturer 1 manages business in Markets 1 and 2 and Manufacturer 2 operates only in Market 1 , under different scenarios, the profits of Manufacturers 1 and 2 abide by the following rules: $\pi_{1}^{S 2} \geq \pi_{1}^{S 1} \geq \pi_{1}^{S 3}$ and $\pi_{2}^{S 1} \geq \pi_{2}^{S 2} \geq \pi_{2}^{S 3}$.

Proposition 2 indicates that the different power structures will affect the independence of price competition. Because consumers in the low WTP market are sensitive to the price, the manufacturer who determines price at the end often has advantages in setting a lower price for the market. In contrast, when making decisions jointly, manufacturers will be highly motivated to reduce prices and ultimately reach a common minimum price to maximize market demand and individual revenue.

Proposition 3 further illustrates that price competition will enable a follower to maintain a lower price and gain more profits, while a pioneer will earn less profits due to a lack of price advantage. However, the price will be minimized when the manufacturers make decisions simultaneously, and the shared "copower" will make them suffer the least benefits in all scenarios.

4.2. Supply Chain Structure with Parallel Import. When the condition is $p_{11} \leq \gamma p_{12}$, the third-party will engage in PI activities. The MNM will compete with his peer in Market 1 and encounter the challenges of parallel import products in Market 2. According to Section 4.1, there are still many possibilities for the manufacturers' power structure. In addition, while the legality of unauthorized sales by the parallel importer is controversial, the MNM will generally resort to a tolerance price strategy $[23,25]$. The parallel importer is the last of the supply chain stakeholders to make the pricing decisions because of the entire dependence on the manufacturers' competitive pricing. Hence, three different power structure scenarios under PI can be determined as follows. The first scenario (GS1) is MNM-led, in which Manufacturer 1 first decides the prices of Markets 1 and 2, Manufacturer 2 determines the price of Market 1, and the parallel importer decides the gray market price in the end. The second scenario 2 (GS2) is LM-led, in which 


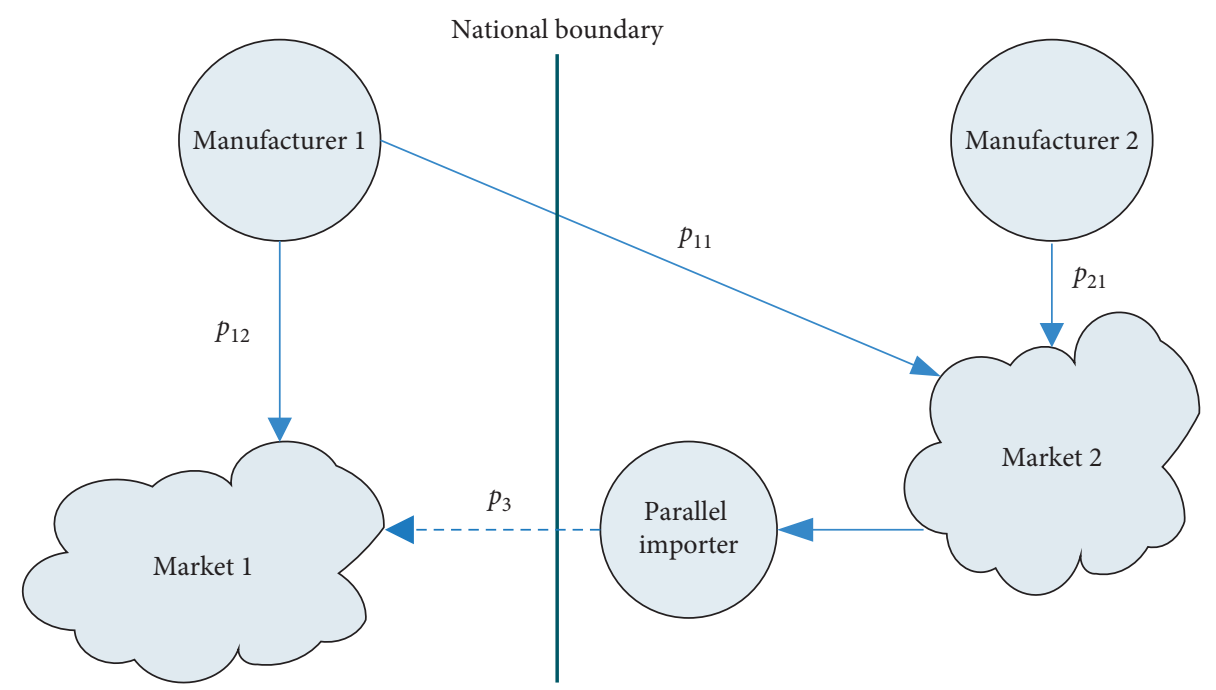

FIGURE 1: Duopoly supply chain competition with PI.

S1 (GS1)

The MNM decides his product prices in markets 1 and 2

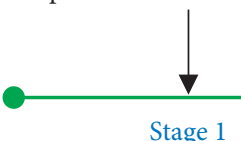

Stage 1
The LM determines her product price in market 2

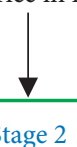

When PI emerges, the third party defines the gray market price

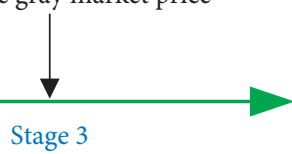

Stage 3

S2 (GS2)

The LM determines her product price in market 2

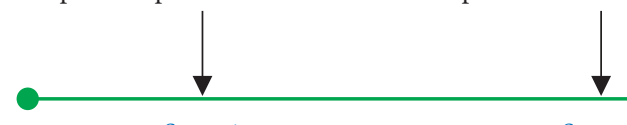

Stage 2 $\begin{array}{c:c}\text { The MNM decides his product } & \text { When PI emerges, the third party } \\ \text { prices in markets } 1 \text { and } 2 & \text { defines the gray market price }\end{array}$ $\begin{array}{c:c}\text { The MNM decides his product } & \text { When PI emerges, the third part } \\ \text { prices in markets } 1 \text { and } 2 & \text { defines the gray market price }\end{array}$

\section{S3 (GS3)}

Both the multinational and local manufacturers determine the market prices of their products simultaneously.

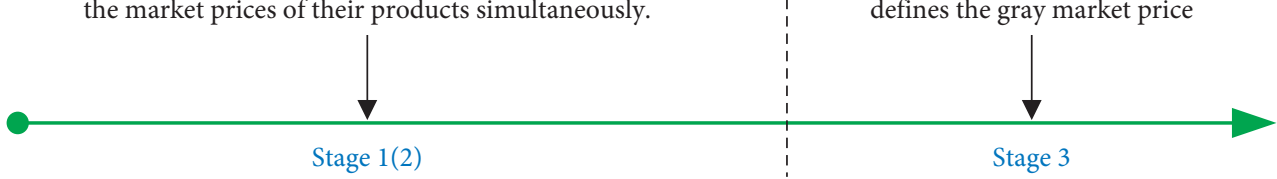

Figure 2: The game sequence.

TABLE 1: Optimal solutions.

\begin{tabular}{lccc}
\hline Decision variable & S1 & S2 & S3 \\
\hline$p_{11}$ & $\bar{v}_{1}(2+\eta) / 2\left(2-\eta^{2}\right)$ & $\bar{v}_{1}\left(4+2 \eta-\eta^{2}\right) / 4\left(2-\eta^{2}\right)$ & $\bar{v}_{1} /(2-\eta)$ \\
$p_{12}$ & $\bar{v}_{2} / 2$ & $\bar{v}_{2} / 2$ & \\
$p_{21}$ & $\bar{v}_{1}\left(4+2 \eta-\eta^{2}\right) / 4\left(2-\eta^{2}\right)$ & $\bar{v}_{1}(2+\eta) / 2\left(2-\eta^{2}\right)$ & $\bar{v}_{1} /(2-\eta)$ \\
$q_{11}$ & $(1 / 2)+(\eta / 4)$ & $\left(4+2 \eta-\eta^{2}\right) / 4\left(2-\eta^{2}\right)$ & $1 /(2-\eta)$ \\
$q_{12}$ & 0.5 & 0.5 & 0.5 \\
$q_{21}$ & $\left(4+2 \eta-\eta^{2}\right) / 4\left(2-\eta^{2}\right)$ & $(1 / 2)+(\eta / 4)$ & $1 /(2-\eta)$ \\
\hline
\end{tabular}


Manufacturer 2 first fixes the price, Manufacturer 1 then sets the price of Markets 1 and 2, and the parallel importer ultimately makes the choice. The third scenario (GS3) is the two collective manufacturers-led scenario, in which Manufacturers 1 and 2 ascertain the price of two markets simultaneously, and the parallel importer finally defines the product price. The decision sequence of stakeholders in different scenarios is illustrated in Figure 2. Hence, the profit functions for Manufacturers 1 and 2, and the parallel importer are characterized accordingly as

$$
\begin{aligned}
& \pi_{1}^{G}=p_{11}\left(q_{11}+q_{3}\right)+p_{12} q_{12}, \\
& \pi_{2}^{G}=p_{21} q_{21}, \\
& \pi_{3}^{G}=\left(p_{3}-p_{11}-t\right) \cdot q_{3} .
\end{aligned}
$$

Under GS1, we derive the equilibrium prices of the manufacturers, and the third-party parallel importer as follows:

$$
\begin{gathered}
P_{11}^{\mathrm{GS} 1}=-\frac{\bar{V}_{1} \bar{V}_{2} \gamma(\gamma \eta+2 \gamma-2 \eta-6)}{A} \\
P_{12}^{\mathrm{GS} 1}=\bar{V}_{2}+\frac{\bar{V}_{2}(\gamma \eta-2)\left(2 \eta \bar{V}_{2}-\bar{V}_{1}\right)}{2 A} \\
P_{21}^{\mathrm{GS} 1}=\frac{\bar{V}_{1}}{4}+\frac{\bar{V}_{1}\left(2 \gamma^{2} \eta \bar{V}_{2}+2 \gamma^{2} \bar{V}_{2}-6 \gamma \eta \bar{V}_{2}-4 \gamma \bar{V}_{2}-2 \bar{V}_{1}\right)}{4 A}, \\
P_{3}^{\mathrm{GS} 1}=\frac{\gamma \bar{V}_{2}}{2}+\frac{\gamma \bar{V}_{2}\left(\gamma \eta^{2} \bar{V}_{2}+\eta \bar{V}_{1}-2 \gamma \bar{V}_{2}+2 \bar{V}_{1}\right)}{2 A}
\end{gathered}
$$

where $A=\gamma^{2} \eta^{2} \bar{V}_{2}-2 \gamma \eta^{2} \bar{V}_{2}-2 \gamma^{2} \bar{V}_{2}+4 \gamma \bar{V}_{2}+2 \bar{V}_{1}$.

Under GS2, we deduce the optimal prices of the manufacturers and the parallel importer as follows:

$$
\begin{aligned}
& P_{11}^{\mathrm{GS} 2}=\frac{\gamma \bar{V}_{1} \bar{V}_{2}\left(\gamma^{3} \eta^{2} \bar{V}_{2}+-2 \gamma^{3} \eta \bar{V}_{2}-5 \gamma^{2} \eta^{2} \bar{V}_{2}-4 \gamma^{3} \bar{V}_{2}+8 \gamma^{2} \eta \bar{V}_{2}+6 \gamma \eta^{2} \bar{V}_{2}+20 \gamma^{2} \bar{V}_{2}-8 \gamma \eta \bar{V}_{2}+24 \gamma \bar{V}_{2}\right)}{4\left(\gamma^{2} \eta^{2} \bar{V}_{2}-2 \gamma \eta^{2} \bar{V}_{2}-2 \gamma^{2} \bar{V}_{2}+4 \gamma \bar{V}_{2}+2 \bar{V}_{1}\right)\left(2 \gamma \bar{V}_{2}-\gamma^{2} \bar{V}_{2}+\bar{V}_{1}\right)} \\
& +\frac{\gamma \bar{V}_{1} \bar{V}_{2}\left(4 \eta \bar{V}_{1}-2 \gamma \eta \bar{V}_{1}-4 \gamma \bar{V}_{1}+12 \bar{V}_{1}\right)}{4\left(\gamma^{2} \eta^{2} \bar{V}_{2}-2 \gamma \eta^{2} \bar{V}_{2}-2 \gamma^{2} \bar{V}_{2}+4 \gamma \bar{V}_{2}+2 \bar{V}_{1}\right)\left(2 \gamma \bar{V}_{2}-\gamma^{2} \bar{V}_{2}+\bar{V}_{1}\right)} \\
& P_{12}^{\mathrm{GS} 2}=\frac{\bar{V}_{2}\left(-4 \gamma^{4} \eta^{2} \bar{V}_{2}^{2}+\gamma^{3} \eta^{2} \bar{V}_{1} \bar{V}_{2}-+12 \gamma^{3} \eta^{2} \bar{V}_{2}^{2}-2 \gamma^{3} \eta \bar{V}_{1} \bar{V}_{2}+\gamma^{2} \eta^{2} \bar{V}_{1} \bar{V}_{2}+8 \gamma^{4} \bar{V}_{2}^{2}-8 \gamma^{2} \eta^{2} \bar{V}_{2}^{2}-4 \gamma^{3} \bar{V}_{1} \bar{V}_{2}\right)}{4\left(\gamma^{2} \eta^{2} \bar{V}_{2}-2 \gamma \eta^{3} \bar{V}_{2}-2 \gamma^{2} \bar{V}_{2}+4 \gamma \bar{V}_{2}+2 \bar{V}_{1}\right)\left(2 \gamma \bar{V}_{2}-\gamma^{2} \bar{V}_{2}+\bar{V}_{1}\right)} \\
& +\frac{\bar{V}_{2}\left(4 \gamma^{2} \eta \bar{V}_{1} \bar{V}_{2}-4 \gamma \eta^{2} \bar{V}_{1} \bar{V}_{2}-24 \gamma^{3} \bar{V}_{2}^{2}+2 \gamma \eta \bar{V}_{2}^{2}+16 \eta^{2} \bar{V}_{2}^{2}+4 \gamma \bar{V}_{1}^{2}+16 \gamma \bar{V}_{1} \bar{V}_{2}+4 \bar{V}_{1}^{2}\right)}{4\left(\gamma^{2} \eta^{2} \bar{V}_{2}-2 \gamma \eta^{2} \bar{V}_{2}-2 \gamma^{2} \bar{V}_{2}+4 \gamma \bar{V}_{2}+2 \bar{V}_{1}\right)\left(2 \gamma \bar{V}_{2}-\gamma^{2} \bar{V}_{2}+\bar{V}_{1}\right)}, \\
& p_{21}^{\mathrm{GS} 2}=\frac{\bar{V}_{1}\left(\gamma^{2} \eta \bar{V}_{2}+2 \gamma^{2} \bar{V}_{2}+3 \gamma \eta \bar{V}_{2}-4 \gamma \bar{V}_{2}-2 \bar{V}_{1}\right)}{\gamma^{2} \eta^{2} \bar{V}_{2}-2 \gamma \eta^{2} \bar{V}_{2}-2 \gamma^{2} \bar{V}_{2}+4 \gamma \bar{V}_{2}+2 \bar{V}_{1}} \\
& P_{3}^{\mathrm{GS} 2}=\frac{\gamma \bar{V}_{2}\left(-2 \gamma^{4} \eta^{2} \bar{V}_{2}^{2}+3 \gamma^{2} \eta^{2} \bar{V}_{1} \bar{V}_{2}+6 \gamma^{3} \eta^{2} \bar{V}_{2}^{2}+4 \gamma^{4} \bar{V}_{2}^{2}-4 \gamma^{2} \eta^{2} \bar{V}_{2}^{2}-2 \gamma^{2} \eta \bar{V}_{1} \bar{V}_{2}-5 \gamma \eta^{2} \bar{V}_{1} \bar{V}_{2}\right)}{4\left(\gamma^{2} \eta^{2} \bar{V}_{2}-2 \gamma \eta^{2} \bar{V}_{2}-2 \gamma^{2} \bar{V}_{2}+4 \gamma \bar{V}_{2}+2 \bar{V}_{1}\right)\left(2 \gamma \bar{V}_{2}-\gamma^{2} \bar{V}_{2}+\bar{V}_{1}\right)} \\
& -\frac{\gamma \bar{V}_{2}\left(12 \gamma^{3} \bar{V}_{2}^{2}+12 \gamma^{2} \bar{V}_{1} \bar{V}_{2}-4 \gamma \eta \bar{V}_{1} \bar{V}_{2}-8 \gamma^{2} \bar{V}_{2}^{2}-2 \eta \bar{V}_{1}^{2}-20 \gamma \bar{V}_{1} \bar{V}_{2}-8 \bar{V}_{1}^{2}\right)}{4\left(\gamma^{2} \eta^{2} \bar{V}_{2}-2 \gamma \eta^{2} \bar{V}_{2}-2 \gamma^{2} \bar{V}_{2}+4 \gamma \bar{V}_{2}+2 \bar{V}_{1}\right)\left(2 \gamma \bar{V}_{2}-\gamma^{2} \bar{V}_{2}+\bar{V}_{1}\right)} .
\end{aligned}
$$

Under GS3, the equilibrium prices of the manufacturers and the importer are as below:

$$
\begin{aligned}
& p_{11}^{\mathrm{GS} 3}=-\frac{\bar{v}_{1} \bar{v}_{2} \gamma((\gamma-2)(\eta-2)-2)}{\gamma^{2} \eta^{2} \bar{v}_{2}-2 \gamma \eta^{2} \bar{v}_{2}-4 \gamma^{2} \bar{v}_{2}+8 \gamma \bar{v}_{2}+4 \bar{v}_{1}}, \\
& p_{12}^{\mathrm{GS} 3}=\bar{v}_{2}+\frac{\bar{v}_{2}\left(\gamma \eta^{2} \bar{v}_{2}+\gamma \eta \bar{v}_{1}+2 \gamma \bar{v}_{1}-4 \gamma \bar{v}_{2}-2 \bar{v}_{1}\right)}{\gamma^{2} \eta^{2} \bar{v}_{2}-2 \gamma \eta^{2} \bar{v}_{2}-4 \gamma^{2} \bar{v}_{2}+8 \gamma \bar{v}_{2}+4 \bar{v}_{1}}, \\
& p_{21}^{\mathrm{GS} 3}=\frac{\bar{v}_{1}\left(-\gamma^{2} \eta \bar{v}_{2}-2 \gamma^{2} \bar{v}_{2}+3 \gamma \eta \bar{v}_{2}+4 \gamma \bar{v}_{2}+2 \bar{v}_{1}\right)}{\gamma^{2} \eta^{2} \bar{v}_{2}-2 \gamma \eta^{2} \bar{v}_{2}-4 \gamma^{2} \bar{v}_{2}+8 \gamma \bar{v}_{2}+4 \bar{v}_{1}},
\end{aligned}
$$

$$
p_{3}^{\mathrm{GS} 3}=\frac{\gamma \bar{v}_{2}}{2}+\frac{\gamma \bar{v}_{2}\left(\gamma \eta^{2} \bar{v}_{2}+2 \eta \bar{v}_{1}-4 \gamma \bar{v}_{2}+4 \bar{v}_{1}\right)}{2\left(\gamma^{2} \eta^{2} \bar{v}_{2}-2 \gamma \eta^{2} \bar{v}_{2}-4 \gamma^{2} \bar{v}_{2}+8 \gamma \bar{v}_{2}+4 \bar{v}_{1}\right)}
$$

Proposition 4. When the markets face PI under different power structures,

(1) Manufacturer 1's prices in Markets 1 and 2 meet $p_{11}^{G S 1} \geq p_{11}^{G S 2} \geq p_{11}^{G S 3} \quad$ and $\quad p_{12}^{G S 1} \geq p_{12}^{G S 2} \geq p_{12}^{G S 3}$, respectively

(2) Manufacturer 2's pricing in Market 1 is subject to $p_{21}^{G S 2} \geq p_{21}^{G S 1} \geq p_{21}^{G S 3}$ 
(3) The parallel importer's pricing follows
$p_{3}^{G S 1} \geq p_{3}^{G S 2} \geq p_{3}^{G S 3}$ in

Proposition 5. When PI emerges, the profits of Manufacturers 1 and 2 in different power structures obey $\pi_{1}^{G S 2} \geq \pi_{1}^{G S 1} \geq \pi_{1}^{G S 3}$ and $\pi_{2}^{G S 1} \geq \pi_{2}^{G S 2} \geq \pi_{2}^{G S 3}$.

Proposition 4 illustrates, first, that the PI has led to the destruction of the separate market established by the MNM, resulting in the nonmonopoly of the high WTP market and market share erosion, ultimately creating high-price markets with differentiated pricing under different power models. Second, it illustrates that the MNM has an incentive to charge higher prices in the low-price market to counter PI but faces price competition and power structures in the selection of different pricing strategies. Third, both manufacturers, regardless of who chairs the emerging market, tend to raise prices compared to other cases and reach a minimum in joint decision-making, which affects the gray product's pricing accordingly.

PI activities affect the participants' benefits, and Proposition 5 reflects the revenue ranking in different scenarios, although the insights are similar to the model without PIs that price competition makes postaction gain more beneficial than preaction. In addition, there are reasons responsible for $\pi_{1}^{\mathrm{GS} 2} \geq \pi_{1}^{\mathrm{GS} 1} \geq \pi_{1}^{\mathrm{GS} 3}$. To manage PI, on the one hand, Manufacturer 1 under GS1 will use high prices in Market 1 to deter the importer so that it will lose its share in Market 1 and adjust the price in Market 2 simultaneously. On the other hand, Manufacturer 1 under GS2 will gain market share by lowering price through postaction and lowering the price in Market 2 to match the importer's competition. In terms of effect, the final revenue under GS2 is higher than that of GS1. In addition, Manufacturers 1 and 2 under GS3 will fiercely compete for market share and lead to the lowest prices, as the authorized products in Market 2 are encroached, resulting in a large profit loss. As a result, the MNM's revenue reaches a minimum under GS3.

Proposition 6. When PI emerges, the MNM's demand in the high WTP market follows $q_{12}^{G S 1}=q_{12}^{G S 2}=q_{12}^{G S 3}=1 / 2$ under market power structures.

Proposition 6 states that if the transaction costs are zero, the MNM's demand in the high WTP market is not affected by parallel importation and market structures, whereas, despite the loss of monopoly power in the high-priced market and the PI's encroachment on market share, the MNM will sustain the same product demand as if there were no PI to reduce the total loss.

Corollary 1. When the PI occurs, the MNM's pricing in the high WTP market satisfies $p_{12}^{S 1}<p_{12}^{G S 1}, p_{12}^{S 2}<$ $p_{12}^{G S 2}$, and $p_{12}^{S 3}<p_{12}^{G S 3}$ under different power structures.

Corollary 1 illustrates that, in cases where PI progressively encroaches on a high WTP market, the MNM will rationally choose a low price irrespective of power structures to preserve demand stability. The reason for this is that the MNM will sell the product at $1 / 2 \bar{v}_{2}$ when no parallel market occurs, and as gray products are flooded into the market, the only way to maintain the original demand is price reduction, which will make it impossible for the MNM to compete adequately with LMs on price in the low price market.

Proposition 7. When the multinational supply chain members compete in the low WTP market, as long as $R<\alpha$ is satisfied, regardless of what the power structure is, the importer will be unprofitable; in contrast, PI will surely be better off than before if $R \geq \psi$, where $\alpha=2 /(2-\eta) \gamma$ and $\Psi=2+\eta / \gamma\left(2-\eta^{2}\right)$.

Although market power among stakeholders will influence returns, Proposition 7 demonstrates that the PI's challenges to manufacturers will disappear as long as $R$ is below a specific threshold. Therefore, on the one hand, the MNM reduces the WTP ratio between Markets 2 and 1, which means the MNM should not launch products in a market with gap that is too large from the high-price market; on the other hand, the MNM should increase the product substitution rate with Manufacturer 2 through marketing strategies or reduce the awareness of product quality. Conversely, these methods will benefit parallel importers and damage manufacturers' benefits. In reality, in the three power structures, the MNM will only care about the high WTP market to keep profits if the product valuation differential between Markets 1 and 2 is significant. The smaller the market difference, the more likely it is for the MNM to consider the two markets to obtain more profits and adopt the tolerance pricing strategy. In contrast, the manufacturer will focus on Market 2 and improve Market 1's price, even eventually giving up the low-priced market. The reason for this is that the lower the consumer's willingness to pay, the more the MNM has to set less expensive prices for the market, which will increase the risk of parallel imports that encroach on the high WTP market.

Proposition 8. If there is a multinational supply chain with two markets, where Market 1 is a low WTP market with price competition, while Market 2 contains PI products,

(1) For Manufacturer 1, (1a) regardless of who becomes a Stackelberg leader single-handedly, the profits will worsen than before, namely, $\pi_{1}^{S 1} \geq \pi_{1}^{G S 1}$ and $\pi_{1}^{S 2} \geq \pi_{1}^{G S 2}$; (1b) if the manufacturers dominate the market simultaneously, the profits depend on the threshold of the WTP ratio in markets, namely,

$$
\frac{\bar{v}_{2}}{\bar{v}_{1}} \begin{cases}>\beta, & \text { then, } \pi_{1}^{\mathrm{S} 3}>\pi_{1}^{\mathrm{GS} 3}, \\ =\alpha \text { or } \beta & \text { then, } \pi_{1}^{\mathrm{S} 3}=\pi_{1}^{\mathrm{GS} 3}, \\ <\beta \text { and }>\alpha & \text { then, } \pi_{1}^{\mathrm{S} 3}<\pi_{1}^{\mathrm{GS} 3},\end{cases}
$$

$$
\text { where } \quad \beta=1 / \gamma(2 \eta)^{2}(2+\eta)^{2}(2-\gamma)(8-(\eta+
$$$$
\text { 2) } \left.\left(\gamma \eta^{2}-2 \eta^{2}-4 \eta+4 \gamma\right)+\sqrt{\beta_{1}}\right) \text { and }
$$ 


$$
\begin{aligned}
\beta 1= & (2-\gamma)^{2} \eta^{6}+\left(4 \gamma^{2}-24 \gamma+32\right) \eta^{5}+\left(12 \gamma^{2}-64 \gamma+96\right) \eta^{4}+\left(32 \gamma^{2}-112 \gamma+96\right) \eta^{3} \\
& +\left(48 \gamma^{2}-160 \gamma+64\right) \eta^{2}+\left(64 \gamma^{2}-320 \gamma+384\right) \eta+64(3-\gamma)^{2}
\end{aligned}
$$

(2) For Manufacturer 2, her revenue will always be better off than before regardless of the power structure, namely, $\pi_{2}^{S 1} \leq \pi_{2}^{G S 1}, \pi_{2}^{S 2} \leq \pi_{2}^{G S 2}$, and $\pi_{2}^{S 3} \leq \pi_{2}^{G S 3}$.

Proposition 8 indicates that the MNM's benefit will be impaired regardless of the power structure, as long as the PI occurs, and the LM will always gain more revenues. In response to the threat, the MNM has to raise prices in the low WTP market, but to achieve a greater share in the market, the MNM requires a lower price. The final trade-off is that the MNM reduces the price in the high WTP market and adopts price management in the low WTP market, namely, an appropriately high-price deterrence under GS1 and a price adjustment under GS2, where both strategies only reduce the MNM's losses. Under GS3, an interval exists between the high and the low WTP market ratios $[\alpha, \beta]$, where the MNM improves the benefits through the price reduction strategy, but it suffers losses when the market gap exceeds the threshold $\beta$. As PIs certainly discourage the MNM from price competition in the low WTP market, the LM acquires a price advantage and earns more profits.

Proposition 9. When confronting PI, the power structures impact the manufacturers' competition if

(1) The MNM is the market leader, the price competition in the low WTP market will be restrained, and Manufacturers 1 and 2 lack the incentive to reduce prices, namely, $p_{11}^{G S 1} \geq p_{11}^{S 1}$ and $p_{21}^{G S 1} \geq p_{21}^{S 1}$

(2) The LM is the market leader, the price competition in the low WTP market will be promoted, and Manufacturers 1 and 2 have the motivation to reduce the price, namely, $p_{11}^{G S 2} \leq p_{11}^{S 2}$ and $p_{21}^{G S 2} \leq p_{21}^{S 2}$

(3) Both Manufacturers 1 and 2 dominate the market simultaneously, the price competition in the market will be restricted, and they have no intention of lowering the price, namely, $p_{11}^{G S 3} \geq p_{11}^{S 3}$ and $p_{21}^{G S 3} \geq p_{21}^{S 3}$

Proposition 9 describes the choices of the manufacturers in power modes to deal with PI challenges. Under GS1 and GS3, the MNM with market power has the motivation to deter the parallel importer with high prices (i.e., $p_{11}^{G S 1} \geq p_{11}^{S 1}$ or $\left.p_{11}^{G S 3} \geq p_{11}^{S 3}\right)$, which enables the LM to obtain more market shares and benefits without a lower price (i.e., $p_{21}^{G S 1} \geq p_{21}^{S 1}$ or $\left.p_{21}^{G S 3} \geq p_{21}^{S 3}\right)$. Therefore, the emergence of PI in these scenarios will impede price competition and cause the loss of consumer welfare in the low-price market. In contrast, the LM under GS2 is the unique market leader who determines price first. To reduce the loss, the MNM will participate in Market 1's competition at a lower price (i.e., $p_{11}^{G S 2} \leq p_{11}^{S 2}$ ) and adjust Market 2's price at the same time to tolerate PI. In an information symmetric market, the LM knows exactly what the MNM's choice is and will first choose a lower price (i.e., $\left.p_{21}^{G S 2} \leq p_{21}^{S 2}\right)$ which is favorable; in other words, the emergence of parallel imports under GS2 intensifies price competition and improves consumer welfare.

Corollary 2. When there are PI activities, compared with two manufacturers in a codominant market, the MNM, who is the market leader, has the power to further restrain price competition. Manufacturers rarely have incentives to reduce prices, i.e., $\quad p_{11}^{G S 1} \geq p_{11}^{S 1} \geq p_{11}^{G S 3} \geq p_{11}^{S 3}$ and $p_{21}^{G S 1} \geq p_{21}^{S 1} \geq p_{21}^{G S 3} \geq$ $p_{21}^{S 3}$.

Corollary 2 further shows that when the MNM is the only market leader, none of the manufacturers has an incentive to lower prices for market competition. It also implies that GS1 only minimizes the losses because the surging price contributes to deterring parallel imports while rarely gaining market share and profits for the MNM.

Proposition 10. The power structure has an impact on the parallel importer's profits. If $R \geq \psi$ holds, the parallel importer's profits reach the largest under GS3, and the least is under GS1. Specifically, the parallel importer's revenue satisfies $\pi_{3}^{G S 1} \leq \pi_{3}^{G S 2} \leq \pi_{3}^{G S 3}$.

Proposition 10 implies that the parallel importer makes the most profit from codecisions, and the least profit from the MNM's prior decisions. The reason is that the parallel importer's profits largely depend on the multinational manufacturer's pricing. We can observe from Proposition 4 that compared to GS1 and GS2, the MNM's price is substantially reduced under GS3 during the weakest price competition. Moreover, the MNM's late-mover advantage leads to a relatively low price under GS2, and the weakest competition makes the price the highest under GS1.

\section{Numerical Examples and Extensions}

Based on the findings of the above analysis, the market power structure, product substitution rate, and perception quality level have an impact on participants' optimal decisions in different WTP markets. Thus, further clarifying, the extent to which these factors influence supply chain participants' decision-making in the presence and absence of PI activities is introduced in the numerical analysis, which will contribute to identifying how the transaction costs in PI affect the benefits of the MNM, LM, and parallel importer. Considering the economic significance of this research and referring to the literature $[39,41]$, some parameters are set to $\bar{v}_{1}=0.2, \bar{v}_{2}=0.6, \gamma=0.75$, and $\eta=0.85$.

5.1. The Impact of the Ratio of Product Valuation on Revenue. When the price gap between the two markets is minor, consumers will lack the incentive to buy the official product from the PI market, and if the reverse is true, the third party will obtain benefits [5]. Based on the parameters, when the 
ratio of high and low WTP exceeds the threshold value of 2.97, parallel import activities always benefit third-party dealers and jeopardize the MNM, regardless of the changing power structure between manufacturers in the market. Considering $\bar{v}_{1}$ as an exogenous variable while keeping $\bar{v}_{2}$ unchanged and enlarging the difference in the markets' WTP by lowering $\bar{v}_{1}$, it is possible to analyze the change in benefits for the MNM, the LM, and the parallel importer under different market power structures, both before and after the emerging parallel imports. If the initial $R$ is set to 3 , then the starting value of $\bar{v}_{1}$ is 0.2 . Considering that the MNM will not enter the low price market when the WTP differences are too substantial, for comparison purposes, the range of variable $\mathrm{V} 1$ adjusts to an overall decline of $0 \%, 5 \%$, $10 \%, 20 \%, 30 \%$, and $40 \%$. We denote $\nabla i=\pi_{i}^{G}-\pi_{i} / \pi_{i}(i=$ $1,2)$ as the revenue change of manufacturer $i$ with and without the PI market and $\nabla_{3}=\pi_{3}^{J}-\pi_{3} / \pi_{3}(J=0.05,0.1,0.2,0.3,0.4)$ as the parallel importer's revenue change with $\bar{v}_{1}$, where $\pi_{3}$ is the parallel importer's profit when $\bar{v}_{1}=0.2$. The total revenue and the evolution of revenue for the MNM, the LM, and the parallel importer under different scenarios are indicated in Tables 2 and 3 .

Table 2 implies that if the WTP ratio exceeds the threshold of 2.97, the multinational supply chain will be attacked by PI regardless of the market power structure of the two manufacturers; the emergence of PI activities in the high WTP market will always result in an acceleration of the benefits for the LM, and the possibility of an enhancement of the MNM's benefits depends on the WTP ratio; PI results in gains for the third-party parallel importer, with diminishing gains for the respective GS3, GS2, and GS1 models.

Under the PI market, Table 3 illustrates that the impact of the market power structure on the supply chain participant's profitability is significant. As the WTP ratio increases, the MNM's profits continue to decrease in both GS1 and GS2, but the latter's profits decrease more rapidly; in GS3, the revenues increase when the ratio is within a certain threshold, but decrease swiftly after exceeding the threshold. However, as the WTP ratio increases, the LM and the parallel importer have exact reversals with GS1, GS2, and GS3, namely $\nabla_{2}^{\mathrm{GS} 1} \leq \nabla_{2}^{\mathrm{GS} 2} \leq \nabla_{2}^{\mathrm{GS} 3}$ and $\nabla_{3}^{\mathrm{GS} 1} \geq \nabla_{3}^{\mathrm{GS} 2} \geq \nabla_{3}^{\mathrm{GS} 3}$, respectively, for the common ratio. The counterintuitive fact that the parallel importer shows geometrical increases in revenue under GS1 and is much higher than that in other scenarios may explain the price strategy adopted by the multinational manufacturer-dominated market when the ratio is not as large, but the strategy also involves balancing profits in two markets as the ratio increases, resulting in a surge in the parallel importer's earnings.

Therefore, for the MNM, on the one hand, efforts should be made to reduce the ratio between the two markets, i.e., launching the products in the markets with a small WTP gap; on the other hand, under GS1, he achieves the goal of controlling the minimum revenue loss; under GS2, he accomplishes the objective of maximizing the total revenue; under GS3, the MNM fulfills the target that the PI is beneficial to total revenue by controlling the ratio to a reasonable threshold range. Simultaneously, the LM can achieve the goal of increasing total benefits regardless of the scenario, but the total growth in absolute amounts is greater under GS1 and GS2, which suggests the relevance of better communication and coordination among the manufacturers.

\subsection{The Impact of Product Substitution Rate and Perceived} Quality on Participants. In a market with a low WTP, the variation in product substitution rate $\eta$ between the manufacturers has an impact on supply chain participants' benefits under different power structures. Based on the above data, the law of change in revenue for the MNM, the LM, and the parallel importer can be derived for different scenarios with increasing $\eta$ (see Figure 3 ).

Figure 3 illustrates that when the parallel import market is active and the substitution rate in Market 1 increases but product quality perception remains constant, the manufacturers' profits will increase and the parallel importer's benefits will decrease continuously regardless of power structures. In addition, the extent to which the manufacturers' revenues increase and the parallel importer's profits shrink is influenced by the market power structures, with the sole manufacturer dominating or participating in the dominant market causing the slowest growth in revenue and, conversely, following the market leading to the fastest growth in total profits; the parallel importer's returns decline most slowly when the manufacturers are simultaneously dominating the market and the fastest when the MNM is exclusively dominant.

Similarly, the quality perception $\gamma$ of gray products influences supply chain participants' benefits. In view of the assumed parameters, the law of change in benefits of the MNM, the LM, and the parallel importer under scenarios when $\gamma$ changes are available (see Figure 4).

Figure 4 demonstrates that when PI shocks the multinational supply chain if the product quality perception to consumers $\gamma$ increases while holding $\eta$ constant and irrespective of power structures, the MNM's revenue declines, the LM's revenue grows incrementally, and the parallel importer's profit first increases and then decreases to 0 . Additionally, power structures have an impact on the magnitude of changes in revenues for manufacturers and parallel importers, which is similar to Figure 3.

These findings are attributable to the following reasons. First, when parallel imports occur in the high WTP market, the MNM resorts to price reduction, while simultaneously the MNM not only manages parallel import activities in the low WTP market but also competes for market share with peers via low-price strategies. These factors generally result in MNM losses, while the LM and parallel importer gain benefits. Second, when the product substitution rate is increased in the low WTP market, meaning there is product homogeneity of the market, competition for lower prices will damage individual benefits as both manufacturers have potential target markets, and they will rationally choose to raise prices that will objectively lead to diminishing the parallel importer's profits. Third, improving the quality perception means that the difference between gray and 
TABle 2: Participants' benefits.

\begin{tabular}{lcccccccccccccccc}
\hline \multirow{2}{*}{ Decrease rate of $\bar{v}_{1}(\%)$} & \multicolumn{4}{c}{ GS1 vs. S1 } & \multicolumn{4}{c}{ GS2 vs. S2 } & \multicolumn{4}{c}{ GS3 vs. S3 } \\
& $\pi_{1}$ & $\pi_{2}$ & $\pi_{1}^{G}$ & $\pi_{2}^{G}$ & $\pi_{3}$ & $\pi_{1}$ & $\pi_{2}$ & $\pi_{1}^{G}$ & $\pi_{2}^{G}$ & $\pi_{3}$ & $\pi_{1}$ & $\pi_{2}$ & $\pi_{1}^{G}$ & $\pi_{2}^{G}$ & $\pi_{3}$ \\
\hline 0 & 0.309 & 0.190 & 0.309 & 0.190 & 0.0000 & 0.340 & 0.159 & 0.330 & 0.167 & 0.0002 & 0.301 & 0.151 & 0.303 & 0.163 & 0.0005 \\
5 & 0.301 & 0.180 & 0.301 & 0.184 & 0.0000 & 0.330 & 0.151 & 0.322 & 0.161 & 0.0004 & 0.294 & 0.144 & 0.295 & 0.157 & 0.0006 \\
10 & 0.293 & 0.171 & 0.292 & 0.178 & 0.0001 & 0.321 & 0.143 & 0.313 & 0.155 & 0.0005 & 0.286 & 0.136 & 0.287 & 0.151 & 0.0009 \\
20 & 0.277 & 0.152 & 0.274 & 0.164 & 0.0004 & 0.302 & 0.127 & 0.294 & 0.142 & 0.0010 & 0.271 & 0.121 & 0.269 & 0.138 & 0.0014 \\
30 & 0.261 & 0.133 & 0.255 & 0.149 & 0.0009 & 0.283 & 0.111 & 0.274 & 0.128 & 0.0016 & 0.256 & 0.106 & 0.250 & 0.124 & 0.0022 \\
40 & 0.245 & 0.114 & 0.234 & 0.134 & 0.0017 & 0.264 & 0.095 & 0.252 & 0.114 & 0.0024 & 0.241 & 0.091 & 0.229 & 0.110 & 0.0033 \\
\hline
\end{tabular}

TABle 3: Participants' profit change ratio.

\begin{tabular}{|c|c|c|c|c|c|c|c|c|c|}
\hline \multirow{2}{*}{ Decrease rate of $\bar{v}_{1}(\%)$} & \multicolumn{3}{|c|}{ GS1 vs. S1 } & \multicolumn{3}{|c|}{ GS2 vs. S2 } & \multicolumn{3}{|c|}{ GS3 vs. S3 } \\
\hline & $\nabla_{1}$ & $\nabla_{2}$ & $\nabla_{3}$ & $\nabla_{1}$ & $\nabla_{2}$ & $\nabla_{3}$ & $\nabla_{1}$ & $\nabla_{2}$ & $\nabla_{3}$ \\
\hline 0 & $0.00 \%$ & $0.30 \%$ & 0.00 & $-2.82 \%$ & $4.95 \%$ & 0.00 & $0.61 \%$ & $7.70 \%$ & 0.00 \\
\hline 5 & $-0.07 \%$ & $2.09 \%$ & 47.59 & $-2.58 \%$ & $6.47 \%$ & 0.57 & $0.43 \%$ & $9.18 \%$ & 0.41 \\
\hline 10 & $-0.24 \%$ & $3.96 \%$ & 172.26 & $-2.43 \%$ & $8.05 \%$ & 1.29 & $0.15 \%$ & $10.72 \%$ & 0.91 \\
\hline 20 & $-0.96 \%$ & $7.97 \%$ & 688.74 & $-2.46 \%$ & $11.42 \%$ & 3.26 & $-0.82 \%$ & $13.98 \%$ & 2.20 \\
\hline 30 & $-2.32 \%$ & $12.39 \%$ & 1632.15 & $-3.07 \%$ & $15.08 \%$ & 6.01 & $-2.44 \%$ & $17.50 \%$ & 3.94 \\
\hline 40 & $-4.49 \%$ & $17.28 \%$ & 3106.22 & $-4.76 \%$ & $19.08 \%$ & 9.72 & $-4.89 \%$ & $21.33 \%$ & 6.22 \\
\hline
\end{tabular}

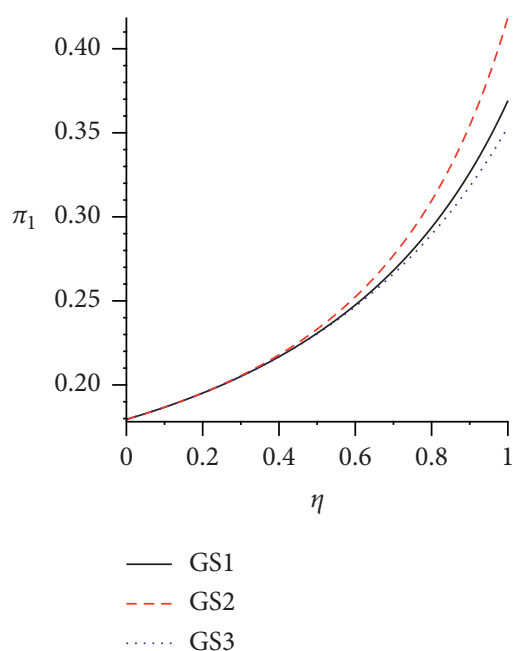

(a)

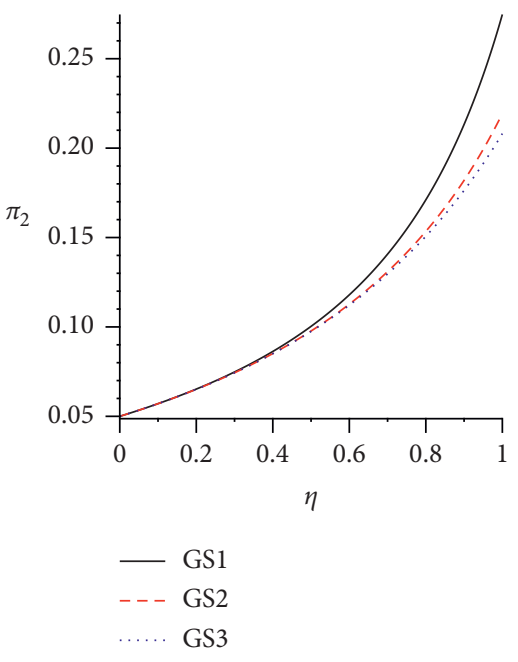

(b)

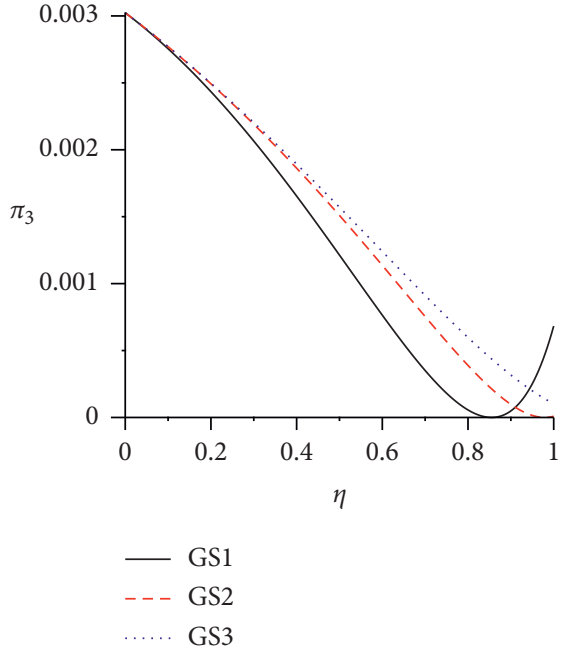

(c)

Figure 3: The impact of $\eta$.

official products becomes minor, which leads to a deterioration of the MNM and benefits the LM and the parallel importer. However, increasing quality perception can cause the MNM to raise the price in the low willingness-to-pay market and induce the parallel importer to raise the price of the gray product and eventually equal the MNM's product price in the high willingness-to-pay market, where the parallel importer's benefits are gradually reduced to zero. Fourth, power structures affect the magnitude of changes in the benefits to the manufacturers and the parallel importer by suppressing or fostering price competition, that is, the manufacturers' postdecisions are more beneficial to themselves, while simultaneously decision-making is the least beneficial, and the parallel importer's benefit rules are reversed.
5.3. The Impact of Transaction Costs in the PI Market on Participants. The fact that transaction costs are widely available in parallel import activities makes for relaxation of model assumptions (i.e., $t \neq 0$ ) in this section, allowing for the analysis of the impact of transaction costs on the product demand of the MNM under different power structures.

Proposition 11. When transaction costs exist in PI activities, the MNM's product demand of the high WTP market follows $q_{12}^{T \ll G S 1}=q_{12}^{T \ll G S 2}=q_{12}^{T \ll G S 3}=2 \bar{v}_{2}(1-\delta)+t / 4 \bar{v}_{2}(1-\delta)>0.5$ under different power structures.

Proposition 11 illustrates that the MNM's demand in the high WTP market has increased at an unprecedented rate and in equal amounts under different scenarios when 

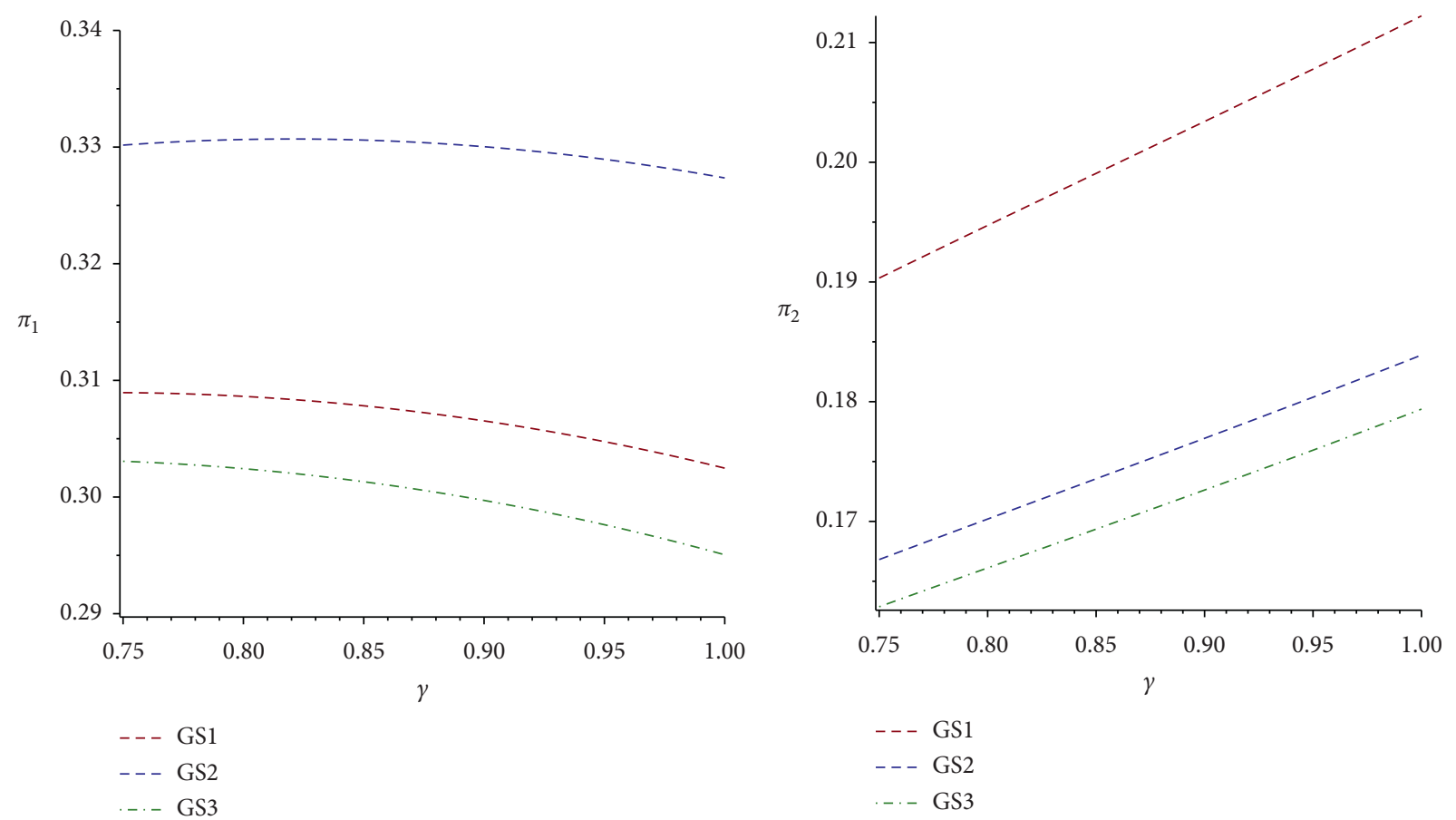

(a)

(b)

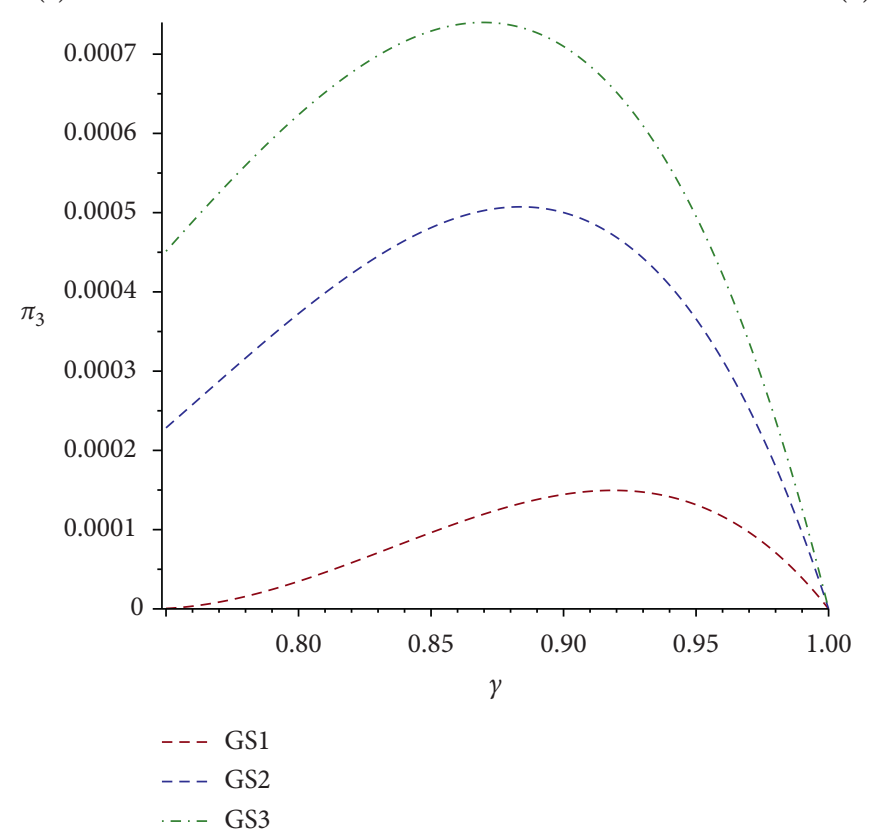

(c)

Figure 4: The impact of $\gamma$.

transaction costs are not negligible and that transaction costs are conducive to discouraging PI. The reason for this is that transaction costs lead to higher prices for gray products in the high WTP market, while the MNM consistently prices the products below $\bar{v}_{2} / 2$ when PI takes place, and some consumers shift demand to the MNM when they buy gray products to obtain a consumer surplus lower than that of official products. Moreover, the MNM, while not being able to monopolize the high-price market, has always held priority decision-making power in the market and can independently determine the quantities that maximize benefits and reduce losses resulting from PI through price regulation.

Furthermore, based on available parametric data and considering a reasonable range of transport costs (i.e., ensuring the parallel importer's nonnegative product demand in the high price market under different scenarios), the pattern of 


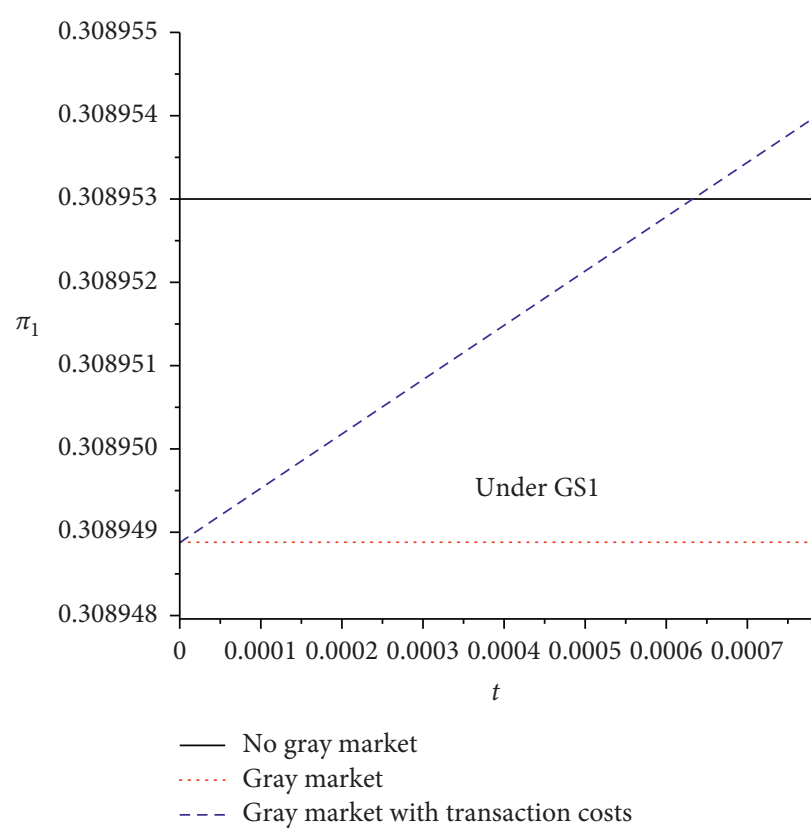

(a)

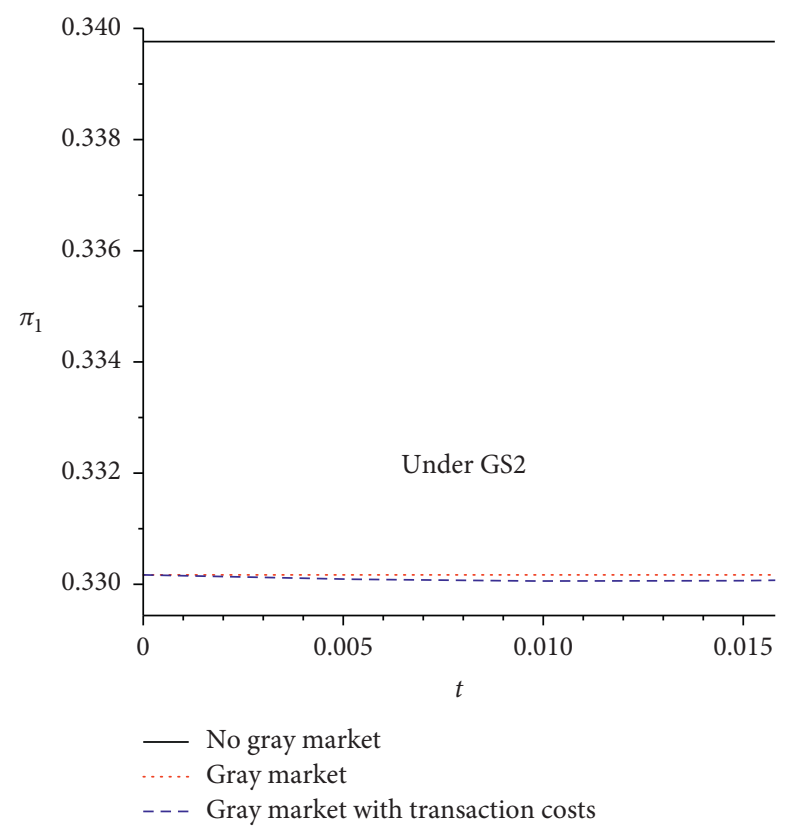

(b)

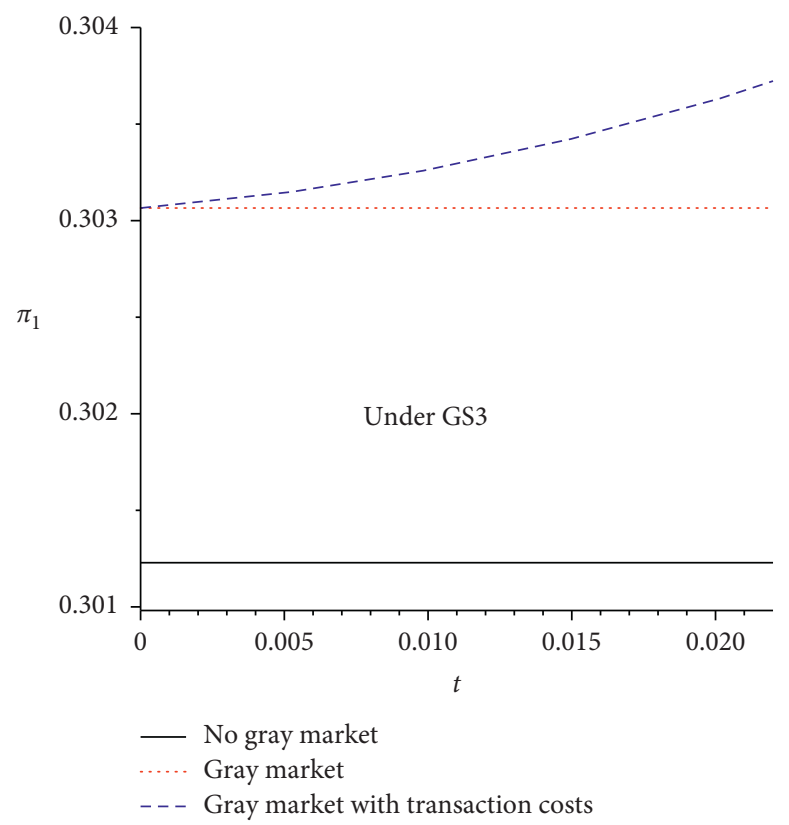

(c)

Figure 5: The impact of transaction costs on the MNM.

change in the impact of transaction costs on the revenue of the supply chain stakeholders under three power structures emerges (Figures 5-7).

Figure 5 shows that, under GS1, the MNM's revenues are diminished owing to PI and that they recover or even increase as transaction costs in PI activities increase. Under GS2, the MNM's revenues are also undermined by PI, and with the increase in transaction costs, the MNM's revenues decrease further and then increase rapidly, exceeding the revenues without $\mathrm{PI}$ at a transaction cost of 0.12 . Under GS3, if the market WTP ratio is in a certain threshold range, PI will further increase the MNM's benefits as transaction costs increase.

Figure 6 reveals that parallel markets are conducive to increasing the LM's benefits regardless of power structures, while the benefits decrease as transaction costs increase. This also suggests that PI activities favor the LM and that transaction costs have a mitigating effect on the manufacturer's profit improvement.

Figure 7 indicates that PI activities generate opportunities for the parallel importer and that the power structure affects the benefits, but the increasing 


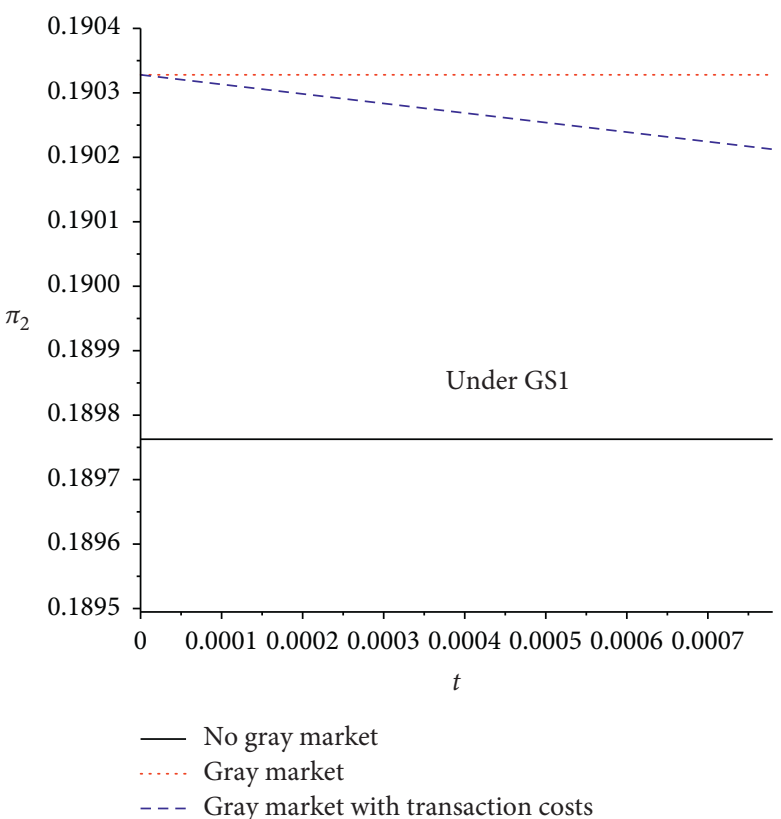

(a)

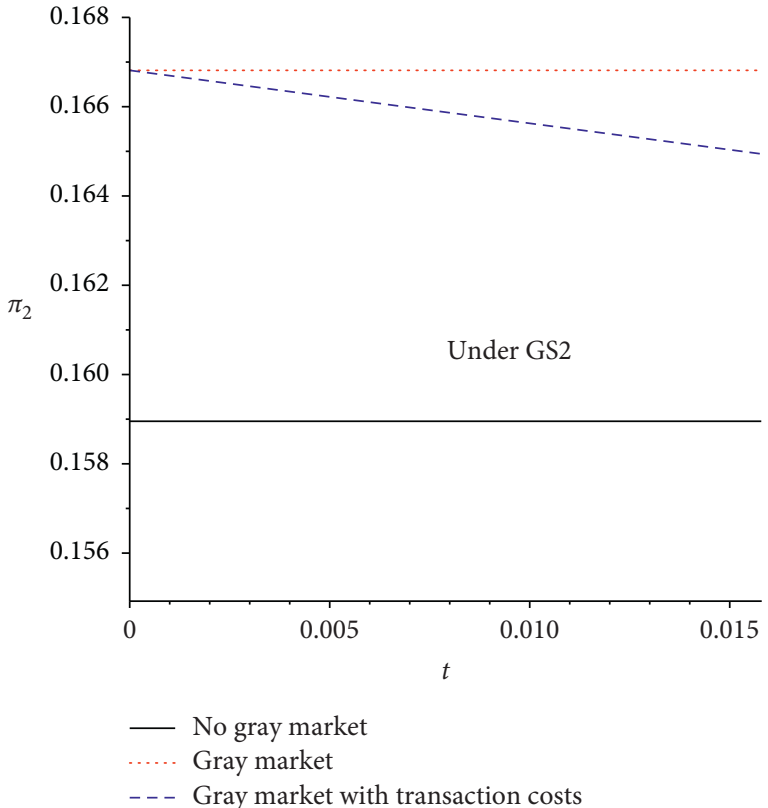

(b)

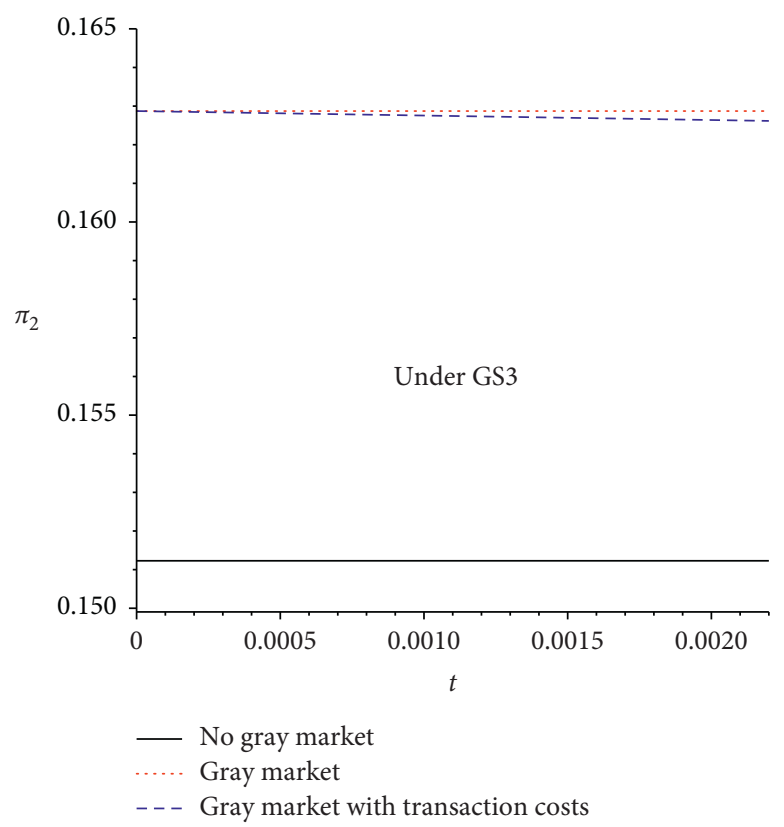

(c)

FIgURE 6: The impact of transaction costs on the LM.

transaction costs lead to a rapid decline in revenues. This also suggests that transaction costs hurt the parallel importer's profitability.
Figures 5-7 demonstrate that power structures and transaction costs shape stakeholders' benefits, but that the latter is more critical for manufacturers' and parallel 


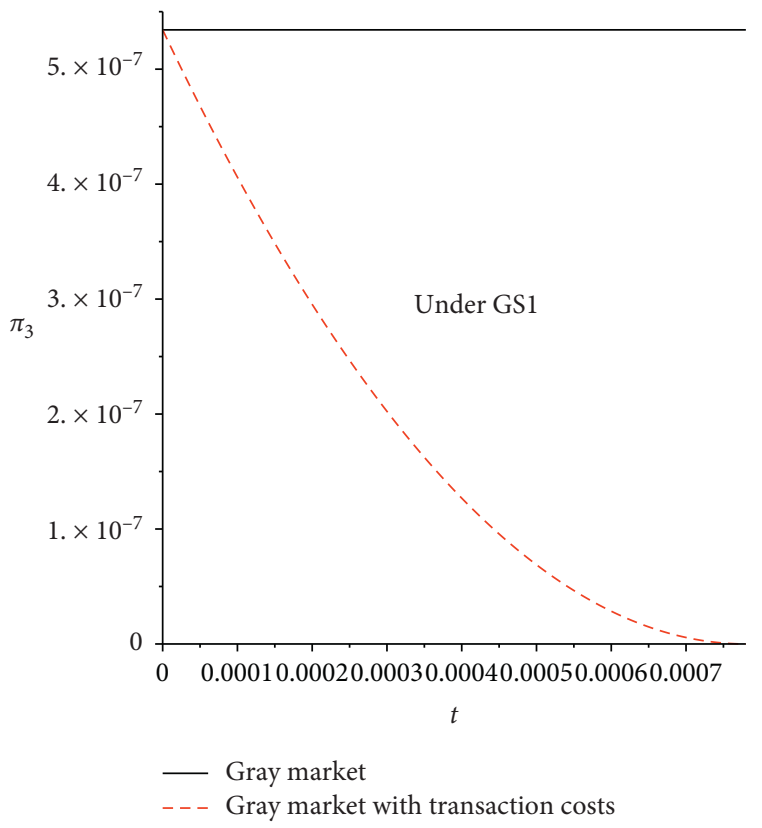

(a)

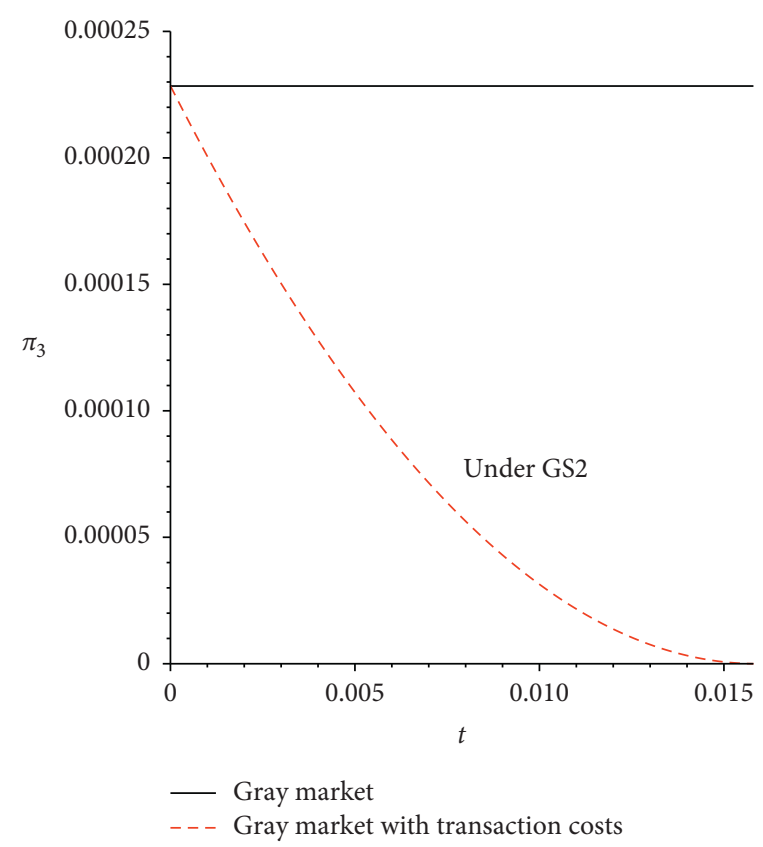

(b)

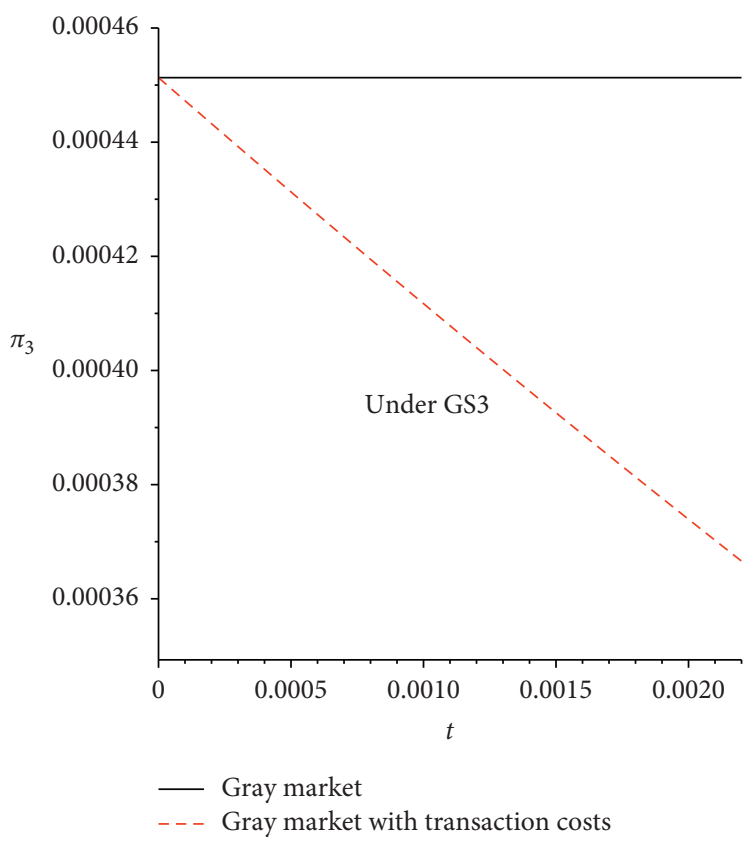

(c)

Figure 7: The impact of transaction costs on the importer.

importers' gains, which are key for reducing losses and even for increasing MNC's benefits, a source of LM benefits improvements, and a PI determinant that cannot be ignored

\section{Conclusions}

Based on the analytical framework of Stackelberg and Nash games, this paper explores price competition in the duopolistic supply chain affected by the PI and examines the impact of power structures on the stakeholders' benefits. The study reveals that the PI does not affect price competition in the supply chain when the ratio of product valuation in high and low WTP markets is smaller than the threshold $\alpha$, and the participants' revenues are mainly determined by power structures. PI will occur and has the effect of promoting or deterring price competition in the supply chain when the 
ratio is greater than or equal to the threshold $\Psi$. A comparison analysis of duopolistic price competition with and without PI activities reveals the following:

(1) Regardless of the PI, the market power structure directly contributes to the manufacturers' gains, the subsequent decision is more conducive to improving the manufacturer's benefits, and the gains are the least when both manufacturers make decisions simultaneously.

(2) When the PI already prevails, the best scenario for the MNM is to have the LM dominate the market, accommodating shares in two markets by moderating prices, and the worst scenario is that the market decision is made concurrently with the LM. In contrast, the LM is profitable irrespective of the power model and reaps the most benefits when the MNM dominates the market.

(3) Where PI exists and two manufacturers place in the identical market status, parallel import activities are conducive to boosting the MNM's revenues if the ratio falls between the interval $[\alpha, \beta]$, and otherwise diminishes the margins.

(4) Irrespective of the market power structure, increasing parallel import transaction costs could enhance the MNM's profits, while simultaneously reducing the LM's revenues and deterring the PI. In addition, either increasing the product substitution rate or quality perception restrains PI and improves LM earnings, but the latter expands the MNM losses.

By utilizing the above game analysis framework, we draw the following managerial insights. (i) From the MNM's perspective, if there is a significant gap between consumers' WTP in the high-price market relative to consumers' WTP in the low-price market, the most straightforward strategy to avoid PI venture is not to launch products in emerging markets. Otherwise, either MNM-led or LM-led market structure is preferable to the manufacturers Nash game. Besides, strengthening cooperation with the local manufacturer (e.g., price information sharing) can effectively control the intensive competition in low-price markets, which reduces the damage of gray products. (ii) From the local manufacturer's perspective, PI activities enable her to gain more market profits, and following the MNMs for decisionmaking is most beneficial. (iii) From the parallel importer's perspective, the diversion of gray products gradually becomes profitless as the manufacturers' price competition weakens and transaction costs increase. (iv) For countries with high-price markets, liberalizing PIs will reduce domestic prices while leading to higher pricing for products in emerging markets.

In this paper, we investigate a supply chain constructed by the MNM and the LM under complete information that is facing PI. The manufacturers' price competition in the low WTP market and the MNM's managing gray market in the high WTP market through price strategy are considered. In the future research, we will discuss MNM's price decisions facing PI under demand uncertainty and analyze the impact of marketing strategies (such as a discount coupon, advertisement, and product warranty) on the pricing decisions of the multinational supply chain with PI. In addition, price competition with other manufacturers in both markets at the same time can be discussed under the PI.

\section{Appendix}

\section{A. Proof of Optimal Solutions of Decision Variables in S1, S2, and S3}

Under S1, we first solve for the LM's profit function, $\operatorname{Max} \pi_{2}=p_{21} q_{21}=p_{21}\left(1-\left(p_{21} / \bar{v}_{1}\right)+\eta\left(p_{11} / \bar{v}_{1}\right)\right)$, and get the second order condition $\left|H_{\pi_{2}\left(p_{21}\right)}\right|=\partial^{2} \pi_{2} / \partial p_{21}^{2}=$ $-\left(2 / \bar{v}_{1}\right)<0$. Thus, the LM's profit function is strictly concave in $p_{21}$, we get the maximum profit when $\partial \pi_{2} / \partial p_{21}=$ $1-\left(\left(2 p_{21}-\eta p_{11}\right) / \bar{v}_{1}\right)=0$, namely, $p_{21}=\left(\bar{v}_{1} / 2\right)+\left(\eta p_{11} / 2\right)$. Then, we bring $p_{21}=\left(\bar{v}_{1} / 2\right)+\left(\eta p_{11} / 2\right)$ into $\operatorname{Max} \pi_{1}=$ $p_{11}\left(1-\left(p_{11} / \bar{v}_{1}\right)+\eta\left(p_{21} / \bar{v}_{1}\right)\right)+p_{12}\left(1-\left(p_{12} / \bar{v}_{2}\right)\right)$, compute the second-order condition and partial derivative of the MNMs profit function, and obtain $\left|H_{\pi_{1}\left(p_{11}, p_{12}\right)}\right|=2(2-$ $\left.\eta^{2}\right) / \bar{v}_{1} \bar{v}_{2}>0, \quad \partial^{2} \pi_{2}\left(p_{11}, p_{12}\right) / \partial p_{11}^{2}=\left(\eta^{2}-2\right) / \bar{v}_{1}<0, \quad$ and $\partial^{2} \pi_{2}\left(p_{11}, p_{12}\right) / \partial p_{12}^{2}=-2 / \bar{v}_{2}<0$ which denotes that the MNM holds the maximum profit when $\partial \pi_{1}\left(p_{11}, p_{12}\right) / \partial p_{11}=$ 0 and $\partial \pi_{1}\left(p_{11}, p_{12}\right) / \partial p_{12}=0$. Then, we solve them and get the optimal solutions as follows: $p_{11}^{S 1}=\bar{v}_{1}(2+\eta) / 2\left(2-\eta^{2}\right)$, $p_{12}^{\mathrm{S} 1}=\bar{v}_{2} / 2, \quad p_{21}^{\mathrm{S} 1}=\bar{v}_{1}\left(4+2 \eta-\eta^{2}\right) / 4\left(2-\eta^{2}\right), \quad q_{11}^{\mathrm{S} 1}=(1 / 2)+$ $(\eta / 4), q_{12}^{\mathrm{S} 1}=1 / 2$, and $q_{21}^{\mathrm{S} 1}=\left(4+2 \eta-\eta^{2}\right) / 4\left(2-\eta^{2}\right)$.

Under S2 and S3, conveniently for a similar approach, we get the optimal solutions as follows: $p_{11}^{\mathrm{S} 2}=\bar{v}_{1}(4+2 \eta-$ $\left.\eta^{2}\right) / 4\left(2-\eta^{2}\right), \quad p_{12}^{\mathrm{S} 2}=\bar{v}_{2} / 2, \quad p_{21}^{\mathrm{S} 2}=\bar{v}_{1}(2+\eta) / 2\left(2-\eta^{2}\right)$, $p_{11}^{\mathrm{S} 2}=\left(4+2 \eta-\eta^{2}\right) / 4\left(2-\eta^{2}\right), q_{12}^{\mathrm{S} 2}=1 / 2, q_{21}^{\mathrm{S} 2}=(1 / 2)+(\eta / 4)$, $p_{11}^{\mathrm{S} 3}=\bar{v}_{1} /(2-\eta), \quad p_{12}^{\mathrm{S} 3}=\bar{v}_{2} / 2, \quad p_{21}^{\mathrm{S} 3}=\bar{v}_{1} /(2-\eta)$, $q_{11}^{\mathrm{S3}}=1 /(2-\eta), q_{12}^{\mathrm{S} 3}=1 / 2$, and $q_{21}^{\mathrm{S3}}=1 /(2-\eta)$.

\section{B. Proof of Optimal Solutions of Decision Variables in GS1, GS2, and GS3}

Under GS1, we solve for the parallel importer's profit function first, $\operatorname{Max} \pi_{3}=\left(p_{3}-p_{11}\right) \cdot 1 / \bar{v}_{2} \gamma(1-\gamma)\left(\gamma p_{12}-p_{3}\right)$, and get the second-order condition $\left|H_{\pi_{3}\left(p_{3}\right)}\right|=$ $\partial^{2} \pi_{3} / \partial p_{3}^{2}=-2 / \bar{v}_{2} \gamma(1-\gamma)<0$. Thus, the profit function is strictly concave in $p_{3}$, we get the maximum profit when $\partial \pi_{3} / \partial p_{3}=0$, namely, $p_{3}=\left(p_{11}+\gamma p_{12}\right) / 2$. Then, we solve for the LM's profit function $\operatorname{Max} \pi_{2}=p_{21}\left(1-\left(p_{21} / \bar{v}_{1}\right)+\right.$ $\left.\eta\left(p_{11} / \bar{v}_{1}\right)\right)$ and get the second order condition $\left|H_{\pi_{2}\left(p_{21}\right)}\right|=$ $\partial^{2} \pi_{2} / \partial p_{21}^{2}<0$ which means that the function is strictly concave in $p_{21}$ and the maximum profit holds when $\partial \pi_{2} / \partial p_{21}=0$, namely, $p_{21}=\left(\bar{v}_{1} / 2\right)+\left(\eta p_{11} / 2\right)$. Next, we bring $p_{21}$ and $p_{3}$ into $\operatorname{Max} \pi_{1}=p_{11}\left(1-\left(p_{11} / \bar{v}_{1}\right)+\eta\right.$ $\left.\left(p_{21} / \bar{v}_{1}\right)\right)+p_{12}\left(1-\left(p_{12} / \bar{v}_{2}\right)\right)$ and compute the 
second-order condition and partial derivative of the MNM's profit function and obtain $\left|H_{\pi_{1}\left(p_{11}, p_{12}\right)}\right|=\left(\bar{v}_{2} \gamma^{2} \eta^{2}+\left(4 \bar{v}_{2} \gamma-\right.\right.$ $\left.\left.2 \bar{v}_{2} \quad \gamma \eta^{2}-2 \bar{v}_{2} \gamma^{2}\right)+2 \bar{v}_{1} / \bar{v}_{1} \bar{v}_{2}^{2} \gamma(1-\gamma)\right)>0, \quad\left(\partial^{2} \pi_{2}\left(p_{11}, p_{12}\right) /\right.$ $\left.\partial p_{11}^{2}=\left(\left(\eta^{2}-2\right) / \bar{v}_{1}\right)-1 / \bar{v}_{2} \gamma(1-\gamma)\right)<0$, and $\partial^{2} \pi_{2}\left(p_{11}, p_{12}\right) /$ $\partial p_{12}^{2}=\left(\gamma-2 / \bar{v}_{2}(1-\gamma)\right)<0$ which denotes that the MNM holds the maximum profit when $\partial \pi_{1}\left(p_{11}, p_{12}\right) / \partial p_{11}=0$ and $\partial \pi_{1}\left(p_{11}, p_{12}\right) / \partial p_{12}=0$. Then, we solve them and get the optimal solutions as equations (12)-(15).

Similar to the processing under GS1, we can get the optimization solutions as equations (16)-(23) under GS2 and GS3.

Proof of Proposition 2. Under S1, because $p_{11}^{*}=\bar{v}_{1}$ $(2+\eta) / 2\left(2-\eta^{2}\right)$ and $p_{21}^{*}=\bar{v}_{1}\left(4+2 \eta-\eta^{2}\right) / 4\left(2-\eta^{2}\right)$, then $p_{11}^{*}-p_{21}^{*}=\bar{v}_{1} \eta^{2} / 4\left(2-\eta^{2}\right)>0$, namely, $p_{11}^{*}>p_{21}^{*}$.

Because $q_{11}^{*}=(1 / 2)+(\eta / 4)$ and $q_{21}^{*}=\bar{v}_{1}\left(4+2 \eta-\eta^{2}\right) / 4$ $\left(2-\eta^{2}\right)$, then $q_{11}^{*}-q_{21}^{*}=\eta^{2}(\eta+1) / 4\left(\eta^{2}-2\right)<0$, namely, $q_{11}^{*}<q_{21}^{*}$.

Under S2, because $p_{11}^{*}=\bar{v}_{1}\left(4+2 \eta-\eta^{2}\right) / 4\left(2-\eta^{2}\right)$ and $p_{21}^{*}=\bar{v}_{1}(2+\eta) / 2\left(2-\eta^{2}\right)$, then $p_{11}^{*}-p_{21}^{*}=\bar{v}_{1} \eta^{2} / 4(2-$ $\left.\eta^{2}\right)<0$, namely, $p_{11}^{*}<p_{21}^{*}$.

Because $\quad q_{11}^{*}=\left(4+2 \eta-\eta^{2}\right) / 4\left(2-\eta^{2}\right)$ and $q_{21}^{*}=$ $(1 / 2)+(\eta / 4)$, then $q_{11}^{*}-q_{21}^{*}=\eta^{2}(\eta+1) / 4\left(2-\eta^{2}\right)>0$, namely, $q_{11}^{*}>q_{21}^{*}$.

In addition, the sum sales of Market 1 in S1 and S2 are $\left(4+2 \eta-\eta^{2}\right) / 4\left(2-\eta^{2}\right)+(1 / 2+t \eta / 4)=\left(8+4 \eta-3 \eta^{2}-\eta^{3}\right) /$ $4\left(2-\eta^{2}\right)$.

Under S3, because $p_{11}^{*}=\bar{v}_{1} /(2-\eta)$ and $p_{21}^{*}=\bar{v}_{1} /(2-\eta)$, then $p_{11}^{*}=p_{21}^{*}$.

And, because $\bar{v}_{1} / 2-\eta-\bar{v}_{1}\left(4+2 \eta-\eta^{2}\right) / 4\left(2-\eta^{2}\right)=$ $-\bar{v}_{1} \eta^{3} / 4\left(2-\eta^{2}\right)(2-\eta)<0$, then $\bar{v}_{1} / 2-\eta<\bar{v}_{1}(4+2 \eta-$ $\left.\eta^{2}\right) / 4\left(2-\eta^{2}\right)$.
Because $q_{11}^{*}=\left(4+2 \eta-\eta^{2}\right) / 4\left(2-\eta^{2}\right)$ and $q_{21}^{*}=(1 / 2)+$ $(\eta / 4)$, then $q_{11}^{*}-q_{21}^{*}=\eta^{2}(\eta+1) / 4\left(2-\eta^{2}\right)>0$, namely, $q_{11}^{*}>q_{21}^{*}$.

Because $q_{11}^{*}=1 / 2-\eta, \quad q_{21}^{*}=1 / 2-\eta$, then $q_{11}^{*}+q_{21}^{*}=$ $2 / 2-\eta$

And, because $\left(8+4 \eta-3 \eta^{2}-\eta^{3}\right) / 4\left(2-\eta^{2}\right)-2 / 2-$ $\eta=\eta^{2}(\eta+2)(\eta-1) / 4\left(2-\eta^{2}\right)(2-\eta)<0$,

then $q_{11}^{*}+q_{21}^{*}>\left(8+4 \eta-3 \eta^{2}-\eta^{3}\right) / 4\left(2-\eta^{2}\right)$.

Hence, both of the manufacturers determine simultaneously which will result in the largest product sales and the equal price in the low WTP market.

Proof of Proposition 3. Because $\pi_{1}^{*}=\left(\bar{v}_{1} \eta^{2}-2 \bar{v}_{2} \eta+\right.$ $\left.4 \bar{v}_{1} \eta+4 \bar{v}_{1}+4 \bar{v}_{2}\right) / 8\left(2-\eta^{2}\right), \quad \pi_{2}^{*}=\bar{v}_{1}\left(\eta^{2}-2 \eta-4\right)^{2} / 16$ $\left(2-\eta^{2}\right)^{2}$ under S1.

Because $\quad \pi_{1}^{*}=\left(\bar{v}_{1} \eta^{4}+4 \bar{v}_{2} \quad \eta^{4}-4 \bar{v}_{1} \eta^{3}-4 \bar{v}_{1} \quad \eta^{2}-\right.$ $\left.16 \bar{v}_{2} \eta^{2}+16 \bar{v}_{1} \eta+16 \bar{v}_{1}+16 \bar{v}_{2}\right) / 16\left(2-\eta^{2}\right)^{2}, \pi_{2}^{*}=\bar{v}_{1}(\eta+2)^{2}$ $/ 8\left(2-\eta^{2}\right)$ under S2, and because $\pi_{1}^{*}=\left(\bar{v}_{2} \eta^{2}-4 \bar{v}_{2} \eta+\right.$ $\left.4 \bar{v}_{1}+4 \bar{v}_{2}\right) / 4\left(2-\eta^{2}\right)^{2}, \pi_{2}^{*}=\bar{v}_{1} /(2-\eta)^{2}$ under S3.

Because $\pi_{1}^{\mathrm{S} 2}-\pi_{1}^{\mathrm{S} 1}=\bar{v}_{1} \eta^{3}(3 \eta+4) / 16\left(2-\eta^{2}\right)^{2}>0$ and $\pi_{1}^{\mathrm{S} 1}-\pi_{1}^{\mathrm{S} 3}=\bar{v}_{1} \eta^{4} / 8\left(2-\eta^{2}\right)(2-\eta)^{2}>0$, then $\pi_{1}^{\mathrm{S} 2} \geq \pi_{1}^{\mathrm{S} 1} \geq \pi_{1}^{\mathrm{S} 3}$.

Because $\pi_{2}^{\mathrm{S} 1}-\pi_{2}^{\mathrm{S} 2}=\bar{v}_{1} \eta^{3}(3 \eta+4) / 16\left(2-\eta^{2}\right)^{2}>0$ and $\pi_{1}^{\mathrm{S} 1}-\pi_{1}^{\mathrm{S} 3}=\bar{v}_{1} \eta^{4} / 8\left(2-\eta^{2}\right)(2-\eta)^{2}>0$, then $\pi_{2}^{\mathrm{S} 1} \geq \pi_{2}^{\mathrm{S} 2} \geq$ $\pi_{2}^{\mathrm{S} 3}$.

Proof of Propositions 4 to 5. Similar to Proposition 2, we omit the process of proving.

Proof of Proposition 7. We define $R=\bar{v}_{2} / \bar{v}_{1}$; then, $\bar{v}_{2}=R \cdot \bar{v}_{1}$, and substitute them into $p_{11}$ and $\gamma p_{12}$.

Meanwhile, we assume $N_{1}=\gamma \eta^{2}-2 \eta^{2}-2 \gamma+4$ :

$$
\begin{aligned}
N= & \frac{1}{4 \gamma N_{1}}\left(\gamma \eta^{2}-2 \gamma \eta-\eta^{2}-4 \gamma+4 \eta+4\right. \\
& +\sqrt{\gamma^{2} \eta^{4}-4 \gamma^{2} \eta^{3}-2 \gamma \eta^{4}-4 \gamma^{2} \eta^{2}+28 \gamma \eta^{3}+\eta^{4}+16 \gamma^{2} \eta+32 \gamma \eta^{2}-40 \eta^{3}-16 \gamma^{2}-80 \gamma \eta-56 \eta^{2}-96 \gamma-96 \eta+144}
\end{aligned}
$$

When existing $p_{11}>\gamma p_{12}$, the threat of parallel imports will disappear. GS3.

So, we get $p_{11}^{\mathrm{GS} 1}>\gamma p_{12}^{\mathrm{GS} 1}$ and $p_{11}^{\mathrm{GS} 3}>\gamma p_{12}^{\mathrm{GS} 3}$ under GS1 and

$$
\begin{aligned}
R^{\mathrm{GS} 2}< & \frac{1}{4 \gamma N_{1}}\left(\gamma \eta^{2}-2 \gamma \eta-\eta^{2}-4 \gamma+4 \eta+4\right. \\
& \quad+\sqrt{\gamma^{2} \eta^{4}-4 \gamma^{2} \eta^{3}-2 \gamma \eta^{4}-4 \gamma^{2} \eta^{2}+28 \gamma \eta^{3}+\eta^{4}+16 \gamma^{2} \eta+32 \gamma \eta^{2}-40 \eta^{3}-16 \gamma^{2}-80 \gamma \eta-56 \eta^{2}-96 \gamma-96 \eta+144}
\end{aligned}
$$

Because $R^{\mathrm{GS} 1}<2+\eta / \gamma\left(2-\eta^{2}\right), R^{\mathrm{GS} 3}<2 /(2-\eta) \gamma$, and $2+\eta / \gamma\left(2-\eta^{2}\right)-2 /(2-\eta) \gamma=\eta^{2} / \gamma(2-\eta)\left(2-\eta^{2}\right)<0$, then $2+\eta / \gamma\left(2-\eta^{2}\right)>2 /(2-\eta) \gamma$. truth

Under GS2, there is $p_{11}^{\mathrm{GS} 2}>\gamma p_{12}^{\mathrm{GS} 2}$. We can induce the 


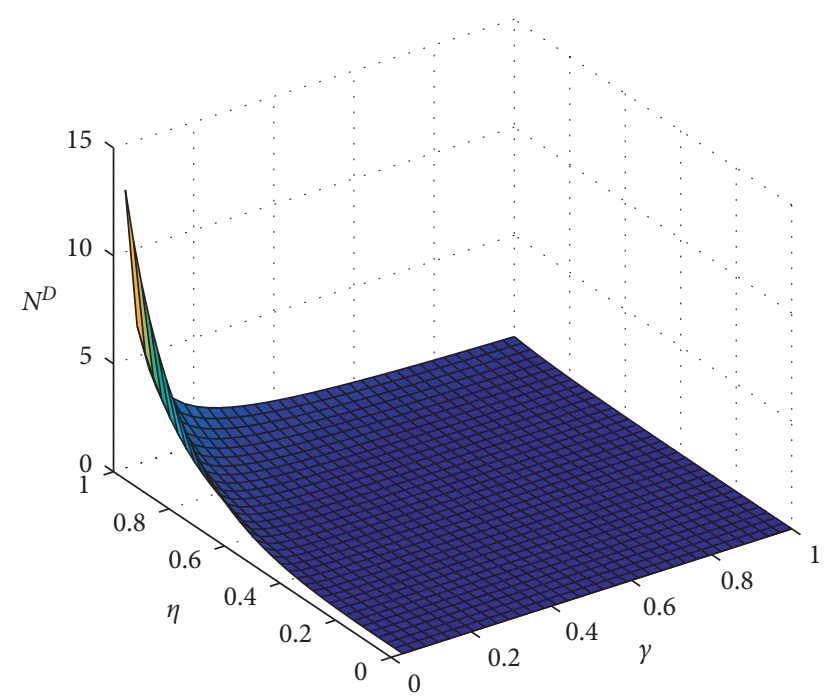

FIgURE 8: Comparison of critical values.

namely, $R^{\mathrm{GS} 2}<N$.

It is hard for us to judge the positive and negative value of $N^{D}=N-2 /(2-\eta) \gamma$. Therefore, we use the drawing function of Matlab to analyze its value, and assume $\gamma$ and $\eta$ between 0 and 1 and get its 3D graphics (see Figure 8), from which we can know that $N \geq 2 /(2-\eta) \gamma$, namely, $\bar{v}_{2} / \bar{v}_{1}<2 /(2-\eta) \gamma$.

In a similar way, we can draw a conclusion that gray market activities are profitable under any market power structure when $\bar{v}_{2} / \bar{v}_{1} \geq\left(2+\eta / \gamma\left(2-\eta^{2}\right)\right)$.

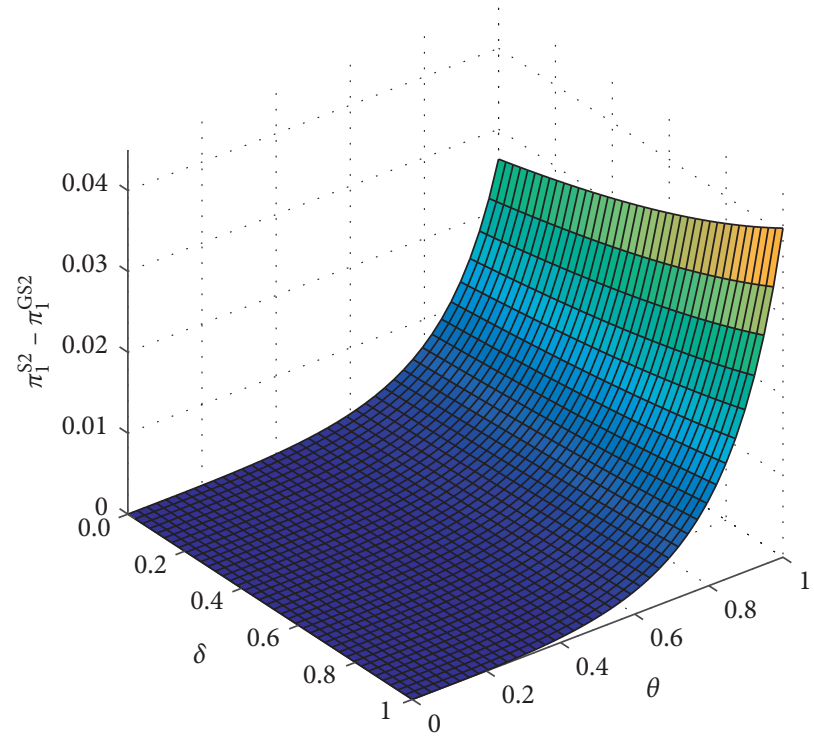

Figure 9: 3D graph of $\pi_{1}^{\mathrm{S} 2}{ }_{1}^{\mathrm{GS} 2}$.

Proof of Proposition 8. The authors can get total revenue of the LM in different scenarios. Hence, $\pi_{2}^{\mathrm{GS} 1}-\pi_{2}^{\mathrm{S} 1}=\bar{v}_{1} \eta\left(\bar{v}_{2}\right.$ $\left.\eta^{2} \gamma+\bar{v}_{1} \eta-2 \bar{v}_{2} \gamma+2 \bar{v}_{1}\right) X_{1} / 4\left(\bar{v}_{2} \eta^{2} \gamma^{2}-2 \bar{v}_{2} \eta^{2} \gamma-2 \bar{v}_{2} \gamma^{2}+4 \bar{v}_{2}\right.$ $\left.\gamma+2 \bar{v}_{1}\right)^{2}\left(2-\eta^{2}\right)^{2}$, where

$$
X_{1}=\left(\bar{v}_{2} \eta^{4} \gamma^{2}-2 \bar{v}_{2} \eta^{3} \gamma^{2}-2 \bar{v}_{2} \eta^{4} \gamma-6 \bar{v}_{2} \eta^{2} \gamma^{2}+5 \bar{v}_{2} \eta^{3} \gamma+4 \bar{v}_{2} \eta \gamma^{2}+12 \bar{v}_{2} \eta^{2} \gamma+3 \bar{v}_{1} \eta^{2}+8 \bar{v}_{2} \gamma^{2}-10 \bar{v}_{2} \eta \gamma-2 \bar{v}_{1} \eta-16 \bar{v}_{2} \gamma-8 \bar{v}_{1}\right)
$$

Because of $\bar{v}_{2}=R \cdot \bar{v}_{1}$ and $R=\left(\bar{v}_{2} / \bar{v}_{1}\right) \geq\left(2+\eta / \gamma\left(2-\eta^{2}\right)\right)$ in GS1, we define $R=2+\eta / \gamma\left(2-\eta^{2}\right)$ and substitute them into the above equation, and there is $\pi_{2}^{\mathrm{S} 1}-\pi_{2}^{\mathrm{GS} 1}=0$. Meanwhile, we assume $R=3+\eta / \gamma\left(2-\eta^{2}\right)$ and put them into the above equation, and there is $\pi_{2}^{\mathrm{S} 1}-\pi_{2}^{\mathrm{GS} 1}=\bar{v}_{1} \eta\left(\eta^{3} \gamma+\right.$ $\left.\eta^{2} \gamma-2 \eta^{3}-10 \eta \gamma-4 \eta^{2}-12 \gamma+25 \eta+32\right) / \quad 4\left(\eta^{2}-2\right)^{2}(\eta \gamma$ $+3 \gamma-2 \eta-8)^{2}>0$. Thus, $\pi_{2}^{\mathrm{GS} 1}-\pi_{2}^{\mathrm{S} 1} \geq 0$, namely, $\pi_{2}^{\mathrm{S} 1} \leq \pi_{2}^{\mathrm{GS} 1}$. Similar to the substitution solution of the above, we can prove $\pi_{2}^{\mathrm{S} 2} \leq \pi_{2}^{\mathrm{GS} 2}$ and $\pi_{2}^{\mathrm{S} 3} \leq \pi_{2}^{\mathrm{GS} 3}$.

For the MNM, we also can get his total revenue in different scenarios.
Under GS1, there is $\pi_{1}^{\mathrm{GS} 1}-\pi_{1}^{\mathrm{S} 1}=\left(\bar{v}_{2} \eta^{2} \gamma+\bar{v}_{1} \eta-2 \bar{v}_{2} \gamma+\right.$ $\left.2 \bar{v}_{1}\right)^{2} / 4\left(\bar{v}_{2} \eta^{2} \gamma^{2}-2 \bar{v}_{2} \eta^{2} \gamma-2 \bar{v}_{2} \gamma^{2}+4 \bar{v}_{2} \gamma+2 \bar{v}_{1}\right)\left(2-\eta^{2}\right) \leq 0$, namely, $\pi_{1}^{\mathrm{S1}} \geq \pi_{1}^{\mathrm{GS} 1}$.

Under GS2, there is $R^{\mathrm{GS} 2} \geq 1 / 4 \gamma N_{1}\left(\gamma \eta^{2}-2 \gamma \eta-\eta^{2}-4 \gamma+\right.$ $4 \eta+4+\sqrt{\gamma^{2} \eta^{4}-4 \eta^{2} \eta^{3}-2 y \eta^{4}-4 \eta^{2} \eta^{2}+28 v \eta^{3}+\eta^{4}+16 \eta^{2} \eta+32 \gamma \eta^{2}-40 \eta^{3}-16 \eta^{2}-80 \eta \eta-56 \eta^{2}-96 \gamma-96 \eta \eta+144}$, where $N_{1}=\gamma \eta^{2}-2 \eta^{2}-2 \gamma+4$. We can also define $R^{\mathrm{GS} 2}=4+2 \eta-\eta^{2} / 2 \gamma\left(2-\eta^{2}\right)$, which is bigger than the threshold value above, and substitute them into the equation of $\pi_{1}^{\mathrm{GS} 2}-\pi_{1}^{\mathrm{S} 2}=\eta^{3}(2+\eta) \quad\left(4+2 \eta-\eta^{2}\right) X_{2} / 16\left(\eta^{2} \gamma-2 \eta \gamma-\right.$ $\left.2 \eta^{2}-4 \gamma+4 \eta+12\right)^{2}\left(\eta^{2} \gamma-2 \eta \gamma-4 \eta^{2}-4 \gamma+4 \eta+12\right)$ $\left.\eta^{2}\right)^{2}$, where

$$
X_{2}=\left(2 \eta^{2} \gamma^{4}-8 \eta^{3} \gamma^{2}-11 \eta^{4} \gamma-8 \eta^{2} \gamma^{2}+42 \eta^{3} \gamma+14 \eta^{4}+32 \eta \gamma^{2}+64 \eta^{2} \gamma-52 \eta^{3}+32 \gamma^{2}-160 \eta \gamma-112 \eta^{2}-192 \gamma+192 \eta+288\right)^{2}
$$


It is hard to judge the value of $\pi_{1}^{\mathrm{S} 2}-\pi_{1}^{\mathrm{GS} 2}$. Therefore, using the drawing function of Matlab to analyze it, we get its 3D graphics (see Figure 9). Then, we can induce $\pi_{1}^{\mathrm{S2}} \geq \pi_{1}^{\mathrm{GS} 2}$.

Under GS3, the equation of $\pi_{1}^{\mathrm{GS} 2}-\pi_{1}^{\mathrm{S} 2}$ is too long and irregular, but we can define $\bar{v}_{2}=R \cdot \bar{v}_{1}$ and substitute it into the equation of $\pi_{1}^{\mathrm{GS} 2}-\pi_{1}^{\mathrm{S} 2}=0$, and the optimal solutions of $R$ are as follows: $\alpha=R_{1}^{*}=2 /(2-\eta) \gamma$ and $\beta=R_{2}^{*}=1 / \gamma(2-\eta)^{2}(2+\eta)^{2}(2-\gamma)(8-(\eta+2)(\gamma$ $\left.\left.\eta^{2}-2 \eta^{2}-4 \eta+4 \gamma\right)+\sqrt{\beta_{1}}\right)$, where

$$
\begin{aligned}
\beta 1= & (2-\gamma)^{2} \eta^{6}+\left(4 \gamma^{2}-24 \gamma+32\right) \eta^{5}+\left(12 \gamma^{2}-64 \gamma+96\right) \eta^{4}+\left(32 \gamma^{2}-112 \gamma+96\right) \eta^{3} \\
& +\left(48 \gamma^{2}-160 \gamma+64\right) \eta^{2}+\left(64 \gamma^{2}-320 \gamma+384\right) \eta+64(3-\gamma)^{2} .
\end{aligned}
$$

If $\eta$ and $\gamma$ vary in the interval of $[0,1]$, we can easily get the truth of $0<\alpha<\beta$ by using the drawing function of Matlab R2016b; thus,

$$
R^{*}=\frac{\bar{v}_{2}}{\bar{v}_{1}} \longrightarrow \begin{cases}>\beta, & \text { then, } \pi_{1}^{\mathrm{S} 3}>\pi_{1}^{\mathrm{GS} 3}, \\ =\alpha \text { or } \beta & \text { then, } \pi_{1}^{\mathrm{S} 3}=\pi_{1}^{\mathrm{GS} 3} \\ <\beta \text {, and }>\alpha & \text { then, } \pi_{1}^{\mathrm{S} 3}<\pi_{1}^{\mathrm{GS} 3}\end{cases}
$$

Proof of Propositions 9 and 10. Similar to Proposition 7, we can easily to prove them by adopting the method of substitution $\left(\bar{v}_{2}=R \cdot \bar{v}_{1}\right)$. Thus, we ignore the proof process.

\section{Data Availability}

The data used to support the findings of this study are available from the corresponding author upon request.

\section{Conflicts of Interest}

The authors declare no conflicts of interest.

\section{Authors' Contributions}

Maozeng $\mathrm{Xu}$ conceived and designed the framework of the paper. Luqing Rong carried out experimental analysis and wrote the paper. Xiaofeng Chen and Zhiping Lu facilitated the problem analysis through constructive discussion.

\section{Acknowledgments}

This research was mainly sponsored by the Chinese National Social Science Foundation under Grant no. 18XGL006, Basic and Frontier Research Projects of Chongqing (no. cstc2020jsyj-zdxwtBX0003), Chongqing Social Science Planning Priorities Project (no. 2020TBWT-ZD002), Philosophy Social Science Planning Project of Guangxi Province in China under Grant no. 15DGL001, and the Promotion Project for Young and Middle-aged Teachers' Basic Scientific Research Ability in Colleges and Universities of Guangxi under Grant no. 2019KY0382.

\section{References}

[1] I. Manuj and J. T. Mentzer, "Global supply chain risk management," Journal of Business Logistics, vol. 29, no. 1, pp. 133-155, 2008.

[2] I. Manuj and J. T. Mentzer, "Global supply chain risk management strategies," International Journal of Physical Distribution \& Logistics Management, vol. 38, no. 3, pp. 192-223, 2008.

[3] B. Niu, F. Xie, Z. Mu, and P. Ji, "Multinational firms' local sourcing strategies considering unreliable supply and environmental sustainability," Resources, Conservation and Recycling, vol. 155, 2020.

[4] M. Christopher, H. Peck, and D. Towill, "A taxonomy for selecting global supply chain strategies," The International Journal of Logistics Management, vol. 17, no. 2, pp. 277-287, 2006.

[5] R. Ahmadi and B. R. Yang, "Parallel imports: challenges from unauthorized distribution channels," Marketing Science, vol. 19, no. 3, pp. 279-294, 2000.

[6] L. P. Bucklin, "Modeling the international gray market for public policy decisions," International Journal of Research in Marketing, vol. 10, no. 4, pp. 387-405, 1993.

[7] P. M. Danzon, "The economics of parallel trade," Pharmaco Economics, vol. 13, no. 3, pp. 293-304, 1998.

[8] H. Hwang, C.-H. Peng, and P.-C. Shih, "Parallel imports, product innovation and market structures," International Review of Economics \& Finance, vol. 34, pp. 237-245, 2014.

[9] R. Ahmadi, F. Iravani, and H. Mamani, "Coping with gray markets: the impact of market conditions and product characteristics," Production and Operations Management, vol. 24, no. 5, pp. 762-777, 2015.

[10] F. Iravani, S. Dasu, and R. Ahmadi, "Beyond price mechanisms: how much can service help manage the competition from gray markets?" European Journal of Operational Research, vol. 252, no. 3, pp. 789-800, 2016.

[11] J. Shao, H. Krishnan, and S. T. McCormick, "Gray markets and supply chain incentives," Production and Operations Management, vol. 25, no. 11, pp. 1807-1819, 2016.

[12] R. Ahmadi, F. Iravani, and H. Mamani, "Supply chain coordination in the presence of gray markets and strategic consumers," Production and Operations Management, vol. 26, no. 2, pp. 252-272, 2017.

[13] J. Costa-Font, "Is medicines parallel trade 'regulatory arbitrage'?" International Journal of Health Economics and Management, vol. 16, no. 4, pp. 321-336, 2016.

[14] R. Autrey and F. Bova, "“Gray markets and multinational transfer pricing," Harvard business school," Harvard Business School Working Papers, vol. 87, 2009.

[15] K. R. Brekke, T. H. Holmås, and O. R. Straume, "Price regulation and parallel imports of pharmaceuticals," Journal of Public Economics, vol. 129, pp. 92-105, 2015. 
[16] M. S. Altug and O. Sahin, "Impact of parallel imports on pricing and product launch decisions in pharmaceutical industry," Production and Operations Management, vol. 28, no. 2, pp. 258-275, 2019.

[17] J. Jie, “3M rules China's mask market," People’s Daily Online, http://en.people.cn/n3/2017/0123/c90000-9170608.html, 2020.

[18] F. Fang, H. Gurnani, and H. P. Natarajan, "Leadership, dominance, and preeminence in a channel structure with a common retailer," Decision Sciences, vol. 49, no. 1, pp. 65-120, 2018.

[19] M. Hu, J. M. Pavlin, and M. Shi, "When gray markets have silver linings: all-unit discounts, gray markets, and channel management," Manufacturing \& Service Operations Management, vol. 15, no. 2, pp. 250-262, 2013.

[20] M. S. Altug, "The dynamics of domestic gray markets and its impact on supply chains," Production and Operations Management, vol. 26, no. 3, pp. 525-541, 2017.

[21] B. C. Y. Lee and C. T. Hsiao, "When does grey market occur? A Cournot duopoly model of intrabrand competition," International Journal of Revenue Management, vol. 2, no. 2, pp. 201-214, 2008.

[22] M. Mazumdar and D. S. Banerjee, "On price discrimination, parallel trade and the availability of patented drugs in developing countries," International Review of Law and Economics, vol. 32, no. 1, pp. 188-195, 2012.

[23] M. Reisinger, L. Saurí, and H. Zenger, "Parallel imports, price controls, and innovation," Journal of Health Economics, vol. 66, pp. 163-179, 2019.

[24] R. L. Autrey, F. Bova, and D. A. Soberman, "When gray is good: gray markets and market-creating investments," Production and Operations Management, vol. 24, no. 4, pp. 547-559, 2015.

[25] H.-L. Chen, "Gray marketing: does it hurt the manufacturers?" Atlantic Economic Journal, vol. 37, no. 1, pp. 23-35, 2009.

[26] H. Raff and N. Schmitt, "Why parallel trade may raise producers' profits," Journal of International Economics, vol. 71, no. 2, pp. 434-447, 2007.

[27] H. Li, S. X. Zhu, N. Cui, and J. Li, "Analysis of gray markets in differentiated duopoly," International Journal of Production Research, vol. 54, no. 13, pp. 4008-4027, 2016.

[28] J. Ishikawa, H. Morita, and H. Mukunoki, "Parallel imports and repair services," Journal of Economic Behavior \& Organization, vol. 172, pp. 137-160, 2020.

[29] H. Huang, Y. He, and J. Chen, "Cross-market selling channel strategies in an international luxury brand's supply chain with gray markets," Transportation Research Part E: Logistics and Transportation Review, vol. 144, Article ID 102157, 2020.

[30] Q. Cao and J. Zhang, "Gray market's product quality in the circular economy era," International Journal of Production Research, vol. 58, no. 2, pp. 1-24, 2019.

[31] Y. Chen and K. E. Maskus, "Vertical pricing and parallel imports," The Journal of International Trade \& Economic Development, vol. 14, no. 1, pp. 1-18, 2005.

[32] N. C. P. Edirisinghe, B. Bichescu, and X. Shi, "Equilibrium analysis of supply chain structures under power imbalance," European Journal of Operational Research, vol. 214, no. 3, pp. 568-578, 2011.

[33] S. C. Choi, "Price competition in a channel structure with a common retailer," Marketing Science, vol. 10, no. 4, pp. 271-296, 1991.

[34] B. R. Yang, R. H. Ahmadi, and K. B. Monroe, "Pricing in separable channels: the case of parallel imports," Journal of Product \& Brand Management, vol. 7, no. 5, pp. 433-440, 1998.
[35] F. Iravani, H. Mamani, and E. Nategh, "External reference pricing and parallel imports of pharmaceuticals: a policy comparison," Production and Operations Management, vol. 29, no. 12, pp. 2716-2735, 2020.

[36] R. L. Autrey, F. Bova, and D. A. Soberman, "Organizational structure and gray markets," Marketing Science, vol. 33, no. 6, pp. 849-870, 2014.

[37] J. Zhang, "The benefits of consumer rebates: a strategy for gray market deterrence," European Journal of Operational Research, vol. 251, no. 2, pp. 509-521, 2016.

[38] H. Huang, Y. He, and J. Chen, "Competitive strategies and quality to counter parallel importation in global market," Omega, vol. 86, pp. 173-197, 2019.

[39] A. A. Taleizadeh, S. Hadadpour, L. E. Cárdenas-Barrón, and A. A. Shaikh, "Warranty and price optimization in a competitive duopoly supply chain with parallel importation," International Journal of Production Economics, vol. 185, pp. 76-88, 2017.

[40] K. Matsui, "Gray-market trade with product information service in global supply chains," International Journal of Production Economics, vol. 147, pp. 351-361, 2014.

[41] H. Shavandi, S. Valizadeh Khaki, and M. Khedmati, "Parallel importation and price competition in a duopoly supply chain," International Journal of Production Research, vol. 53, no. 10, pp. 3104-3119, 2015.

[42] H. Li, J. Shao, and S. X. Zhu, "Impacts of power dynamics and gray markets on supply chains," International Journal of Production Economics, vol. 222, Article ID 107488, 2020.

[43] H. Li, J. Shao, and S. X. Zhu, "Parallel importation in a supply chain: the impact of gray market structure," Transportation Research Part E: Logistics and Transportation Review, vol. 114, pp. 220-241, 2018.

[44] K.-H. Um and S.-M. Kim, "The effects of supply chain collaboration on performance and transaction cost advantage: the moderation and nonlinear effects of governance mechanisms," International Journal of Production Economics, vol. 217, pp. 97-111, 2019.

[45] J. J. Liu, Z. Wang, D.-Q. Yao, and X. Yue, "Transaction cost analysis of supply chain logistics services: firm-based versus port-focal," Journal of the Operational Research Society, vol. 67, no. 2, pp. 176-186, 2016.

[46] M. Ketokivi and J. T. Mahoney, "Transaction cost economics as a theory of supply chain efficiency," Production and Operations Management, vol. 29, no. 4, pp. 1011-1031, 2020.

[47] R. H. Coase, "The nature of the firm," Economica, vol. 4, no. 16, pp. 386-405, 1937.

[48] C. Li and J. Robles, "Product innovation and parallel trade," International Journal of Industrial Organization, vol. 25, no. 2, pp. 417-429, 2007.

[49] Z.-Z. Jiang, J. Zhao, Z. Yi, and Y. Zhao, "Inducing information transparency: the roles of gray market and dual-channel," Annals of Operations Research, 2020.

[50] B. Niu, Q. Li, and L. Chen, "Exclusive vs. competitive retailing: overseas vaccine supplier's channel selection considering profit and social responsibility objectives," Computers \& Industrial Engineering, vol. 144, Article ID 106499, 2020.

[51] Y. Xiao, U. Palekar, and Y. Liu, "Shades of gray-the impact of gray markets on authorized distribution channels," Quantitative Marketing and Economics, vol. 9, no. 2, p. 155, 2011.

[52] A. A. Taleizadeh, F. Akhavizadegan, and J. Ansarifar, "Pricing and quality level decisions of substitutable products in online and traditional selling channels: game-theoretical approaches," International Transactions in Operational Research, vol. 26, no. 5, pp. 1718-1751, 2019. 
[53] Z. Yao, K. K. Lai, C. H. Stephen, and C. Lai, "Manufacturer's revenue-sharing contract and retail competition," European Journal of Operational Research, vol. 186, no. 2, pp. 637-651, 2008.

[54] R. D. Banker, I. Khosla, and K. K. Sinha, "Quality and competition," Management Science, vol. 44, no. 9, pp. 1179-1192, 1998.

[55] S. Roy and K. Saggi, "Equilibrium parallel import policies and international market structure," Journal of International Economics, vol. 87, no. 2, pp. 262-276, 2012.

[56] D. Ghosh and J. Shah, "A comparative analysis of greening policies across supply chain structures," International Journal of Production Economics, vol. 135, no. 2, pp. 568-583, 2012.

[57] J. Wei, J. Zhao, and Y. Li, "Pricing decisions for complementary products with firms' different market powers," European Journal of Operational Research, vol. 224, no. 3, pp. 507-519, 2013. 